University of Nebraska - Lincoln

DigitalCommons@University of Nebraska - Lincoln

$8-2020$

\title{
Connections between the hydrological cycle and crop yield in the rainfed U.S. Corn Belt
}

\author{
Wang Zhou \\ University of Illinois at Urbana-Champaign, wangzhou@illinois.edu \\ Kaiyu Guan \\ University of Illinois at Urbana-Champaign, kaiyug@illinois.edu \\ Bin Peng \\ University of Illinois at Urbana-Champaign \\ Jiancheng Shi \\ Beijing Normal University \\ Chongya Jiang \\ University of Illinois at Urbana-Champaign, chongya@illinois.edu
}

See next page for additional authors

Follow this and additional works at: https://digitalcommons.unl.edu/natrespapers

Part of the Natural Resources and Conservation Commons, Natural Resources Management and Policy Commons, and the Other Environmental Sciences Commons

Zhou, Wang; Guan, Kaiyu; Peng, Bin; Shi, Jiancheng; Jiang, Chongya; Wardlow, Brian; Pan, Ming; Kimball, John S.; Franz, Trenton; Gentine, Pierre; He, Mingzhu; and Zhang, Jingwen, "Connections between the hydrological cycle and crop yield in the rainfed U.S. Corn Belt" (2020). Papers in Natural Resources. 1386. https://digitalcommons.unl.edu/natrespapers/1386

This Article is brought to you for free and open access by the Natural Resources, School of at DigitalCommons@University of Nebraska - Lincoln. It has been accepted for inclusion in Papers in Natural Resources by an authorized administrator of DigitalCommons@University of Nebraska - Lincoln. 


\section{Authors}

Wang Zhou, Kaiyu Guan, Bin Peng, Jiancheng Shi, Chongya Jiang, Brian Wardlow, Ming Pan, John S.

Kimball, Trenton Franz, Pierre Gentine, Mingzhu He, and Jingwen Zhang 
1 Connections between the hydrological cycle and crop yield in the rainfed U.S. Corn Belt

2

Wang Zhou ${ }^{1,3,4^{*}}$, Kaiyu Guan ${ }^{1,2^{*}}$, Bin Peng ${ }^{1,2}$, Jiancheng Shi ${ }^{3}$, Chongya Jiang ${ }^{1}$, Brian

Wardlow ${ }^{5}$, Ming Pan ${ }^{6}$, John S. Kimball ${ }^{7}$, Trenton E. Franz ${ }^{5}$, Pierre Gentine ${ }^{8}$, Mingzhu He ${ }^{7}$, and Jingwen Zhang ${ }^{1}$

${ }^{1}$ College of Agricultural, Consumer and Environmental Sciences, University of Illinois at Urbana-Champaign, Urbana, IL, USA

${ }^{2}$ National Center for Supercomputing Applications, University of Illinois at UrbanaChampaign, Urbana, IL, USA

${ }^{3}$ State Key Laboratory of Remote Sensing Science, Jointly Sponsored by Institute of Remote Sensing and Digital Earth of Chinese Academy of Sciences and Beijing Normal University, Beijing, China

${ }^{4}$ University of Chinese Academy of Sciences, Beijing, China

${ }^{5}$ School of Natural Resources, University of Nebraska-Lincoln, Lincoln, NE, USA

${ }^{6}$ Department of Civil and Environmental Engineering, Princeton University, NJ, USA

${ }^{7}$ Numerical Terradynamic Simulation Group, University of Montana, Missoula, MT, USA

${ }^{8}$ Department of Earth and Environmental Engineering, Earth Institute, Columbia University, New York, NY, USA

Corresponding to: Kaiyu Guan (kaiyug@illinois.edu); Wang Zhou (wangzhou@illinois.edu)

Abstract: Water stress is one of the major abiotic stresses and directly affects crop growth and influences crop yields. To better quantify the responses of crop yield to hydrological variability in the rainfed Corn Belt of the United States (U.S.), we analyzed the relationships between corn/soybean yield and hydrological cycle metrics, as well as their spatio-temporal dynamic at the agricultural district and interannual scale between 2003 and 2014. We used Partial Least Square Regression (PLSR) to optimally integrate different hydrological metrics and drought indices to define a crop-specific new drought index that uses crop yield as the 
target, and investigated the contributions of those hydrological cycle components to the new drought index. We used both observed and modeled hydrological cycle metrics, as well as several drought indices in this study, including evapotranspiration (ET) and potential ET (PET), terrestrial water storage change $(\Delta \mathrm{S})$, surface soil moisture (SSM), river discharge (Q), Standardized Precipitation-Evapotranspiration Index (SPEI), Palmer Drought Severity Index (PDSI), fET (the ratio of ET to PET), and vapor pressure deficit (VPD). Our results revealed that: (1) VPD, SSM, and fET showed the strongest correlations with crop yield, among the observation-based hydrological cycle metrics and drought indices considered here. Most of the hydrological cycle metrics and drought indices showed similar seasonal correlation patterns with crop yield, and this pattern revealed that the sensitivity of crop growth to water stress peaked in July for corn and in August for soybean in the rainfed U.S. Corn Belt. (2) The drought in 2012 started with higher water demand (reflected in abnormally high ET, PET, and VPD) and lower water supply (reflected in abnormally low P), followed by soil water depletion (as revealed in SSM and $\Delta \mathrm{S}$ ), leading to massive crop yield losses due to increased constraints on both water supply and demand. (3) The $\mathrm{R}^{2}$ of the PLSR-based crop yield model reached 0.76 and 0.70 for corn and soybean, respectively. For corn, the first PLSR component was mainly composed of information from VPD, fET and SSM, indicating atmospheric water deficit and near surface soil water storage both play critical roles in quantifying corn yield loss due to water stress. For soybean, the first PLSR component was mainly composed of information from fET, ET and VPD, indicating more controls from atmospheric demand than soil moisture supply for soybean yield loss due to water stress.

Key words: drought, crop yield, soil moisture, VPD, evapotranspiration, groundwater, U.S. Corn Belt

\section{Highlights:}

(1) Water supply and demand is vital in quantifying drought in the U.S. Corn Belt.

(2) The 2012 drought was initiated by high water demand and aggravated by low supply.

(3) New drought indices were developed by integrating water supply and demand.

(4) VPD and fET significantly contribute to the new drought indices. 


\section{Introduction}

The hydrological cycle is expected to accelerate under a warming climate (Huntington, 2006; Oki and Kanae, 2006), with more frequent drought and flooding (Huntington, 2006; Cook et al., 2020) posing significant challenges for agricultural production and food security (Anyamba et al., 2014; Brown and Funk, 2008; Iizumi et al., 2014; Rosenzweig et al., 2001). Rainfed agriculture accounts for $\sim 80 \%$ of global croplands (Biradar et al., 2009), which are prone to more frequent stresses from drought and flooding (Nocco et al., 2019). For example, the Midwestern United States (U.S.) alone produces one third of the global corn and soybean production, and $>90 \%$ of the farmland is rainfed. Understanding the impacts of climatic stresses on agricultural production, especially the influence of hydrological stress on crop yield loss in rainfed regions, is becoming urgently needed (Lobell et al., 2014; Mishra and Cherkauer, 2010; Peng et al., 2020a).

A first gap in the existing studies on agricultural drought is the overemphasis on soil moisture conditions compared to other hydrological stressors. In reality, droughts are multifaceted and have been conventionally classified into four categories: meteorological droughts, hydrological droughts, agricultural droughts, and socio-economic droughts (Mishra and Singh, 2010). In particular, "agricultural droughts" are usually defined primarily based on soil moisture conditions (i.e. plant soil water availability is insufficient for crop growth, affecting end-of-season crop yield) (Bolten et al., 2006, 2010; Crow, 2014; Han et al., 2014). This may lead to an oversimplification that neglects other important environmental factors (Lobell et al., 2014; Ort and Long, 2014). Soil moisture only accounts for the available water in a rainfed system for the crop growth, but it does not include the effects of water demands from the atmosphere. An increasing number of studies emphasize that atmospheric water demand plays a critical role in inducing plant water stress and suppressing crop yield (Lobell et al., 2014; Novick et al., 2016; Sulman et al., 2016). Indicators for atmospheric water demand include Vapor Pressure Deficit (VPD), and/or potential evapotranspiration (PET) (Seager et al., 2015; Milly and Dunne, 2016), which integrates the influences from several 
111 Given the various existing drought metrics, another gap lies in terms of lack of benchmarks 112 for these drought metrics. Many studies on agricultural drought use the Drought Severity meteorological factors like air temperature, humidity, radiation, and wind (Luo et al., 2017). To holistically characterize "agricultural drought", both water supply (from soil) and water demand (from the atmosphere) should be considered, as plant plays a central role in regulating the flow of moisture across the soil-plant-atmosphere continuum (SPAC) in order to maintain an adequate internal water status (Bonan et al., 2014; Ouyang, 2002). SPAC processes include plant hydraulics and plant physiology (Williams et al., 1996), which have been actively discussed in the literature (Martínez-Vilalta et al., 2014; Sperry et al., 2002; Tyree and Ewers, 1991). Plants hydraulics are starting to be implemented in land surface models (Bonan et al., 2014; Kennedy et al., 2019; Xu et al., 2016).

From an empirical perspective, water supply can be approximated using different indices: (1) precipitation, and/or precipitation-related indices, such as Standardized Precipitation Index (SPI) (Hunt et al., 2014; McKee et al., 1993); (2) plant available water content (i.e., the difference between soil water content and wilting point), and/or soil-moisture-related indices, such as Soil Moisture Percentiles (SMP) (Andreadis et al., 2005; Mishra and Cherkauer, 2010); (3) groundwater dynamics, for regions with deep-rooted plants or non-negligible surface-groundwater interactions (Orellana et al., 2012). Atmospheric water demand during crop growth is commonly characterized by VPD and/or PET (Novick et al., 2016). High atmospheric water demand, indicated by a high VPD, can reduce plant stomatal opening and thus reduce the rate of plant photosynthesis (Muller et al., 2011). To take both water supply and water demand into account, some drought indices have been developed, such as fET (=ET/PET) (Anderson et al., 2016b, 2007a, 2007b; Yang et al., 2018), Standardized Precipitation-Evapotranspiration Index (SPEI) (Masud et al., 2015; Vicente-Serrano et al., 2010), and Palmer Drought Severity Index (PDSI) (Palmer, 1965; Dai et al., 2004; Ge et al., 2016; Tian et al., 2018). These drought indices follow similar ideas, but with different mathematical formulations. 
Measure from the U.S. Drought Monitor (USDM) (Anderson et al., 2013; Otkin et al., 2014,

114 2013). However, the USDM metrics for drought are complicated because they represent both

115 short- and long-term drought conditions associated with agricultural and hydrologic droughts

116 respectively, and are based on a broad array of observations (e.g., precipitation, temperature,

117 soil moisture, stream, ET and groundwater) and guidance from drought experts throughout

118 the United States (Svoboda et al., 2002). Thus for "agricultural drought", the USDM metrics

119 may not be the most accurate measure available because of the broad range of drought types

120 and conditions represented that may or may not pertain to crop stress. Crop yield, the ultimate

121 measure for agricultural productivity, is an obvious metric for evaluating drought impacts on

122 agriculture. However, few studies use crop yield to benchmark different drought measures for 123 agricultural drought monitoring.

Another gap in current agricultural drought assessments is the lack of consideration of the variable sensitivity to water stress at different growth stages of the crops. Droughts with the same severity (e.g. measured by different drought indices or hydrological components) but occurring at different growth stages can lead to significantly different impacts (Guan et al., 2015, 2014; Mladenova et al., 2017; Peng et al., 2018a). Water stress that occurs during the critical growth stages usually has a much larger negative impact on the end-of-season yield (Mishra and Cherkauer, 2010; Peng et al., 2018a). The silking and grain-filling stages are the most critical stages for corn grain formation (Hunt et al., 2014; Meyer et al., 1993), which occur 70 to 90 days after planting for corn in the U.S. (i.e. late July and August in the U.S. Corn Belt, where corn is usually planted in early-mid May). As for soybean, the most critical stages for production are the blooming and podding stages (Mishra and Cherkauer, 2010),

137 Belt, where soybean is usually planted in middle May to early June). Water stress during these periods may result in irreversible damage on the end-of-season crop yield. So, it is also

139 necessary to diagnose the influence of water stress on the crop yield at different growth 140 stages. 
142 In this study, we investigate the connections between the hydrological cycle metrics and crop

143 yield variability (for both corn and soybean) across the rainfed area of the U.S. Corn Belt, one

144 of the world's largest crop production areas (Grassini et al., 2015). The majority of the U.S.

145 Corn Belt is rainfed, and it has experienced various levels of drought in the past, including

146 particularly severe droughts in 1988 and 2012 (Rippey, 2015). Understanding how the

147 hydrological cycle affects food production and increasing our ability to predict drought

148 related impacts on crop yield would greatly benefit scientific and practical needs.

149 Specifically, we analyze the relationship between anomalies of hydrological variables and

150 end-of-season crop yields at the agricultural district scale between 2003 and 2014. Both

151 observation-based and model-based hydrological variables (including both hydrological cycle

152 components and some drought indices) are used in this study. We then use advanced

153 statistical modeling to explore optimal ways to define an integral drought index for

154 agricultural drought monitoring, in which stresses from both water supply and demand are

155 considered. Through the analysis, we aim to answer the following questions: (1) What are the

156 best indicators to assess the influence of crop water stress among the hydrological cycle

157 components and commonly used drought indices in the rainfed U.S. Corn Belt, when

158 benchmarked with crop yield? (2) What is the performance of those hydrological cycle

159 components and drought indices as indicators for crop yield losses during the extreme drought

160 year of 2012? (3) How can we optimally integrate those hydrological cycle components and

161 drought indices to assess agricultural drought and what are the contributions of those

162 hydrological cycle components to the new drought index?

\section{Materials and method}

2.1 Study area

166 This study focuses on the rainfed part of the U.S. Corn Belt (Figure 1), where the influence of

167 irrigation on crop yield is minimized. Our study domain is located in the central and eastern

168 parts of the U.S. Midwest. We conducted our analysis at the U.S. Department of Agriculture 
(USDA)-designated agricultural district level (blue boundaries shown in Figure 1), and used monthly hydrological cycle metrics, drought indices and USDA reported end-of-season crop yield data between 2003 and 2014. Our study area is a typical landscape planting corn and soybean (Figure 1), representing approximately $60 \%$ and $56 \%$ of the U.S. total corn and soybean production, respectively.

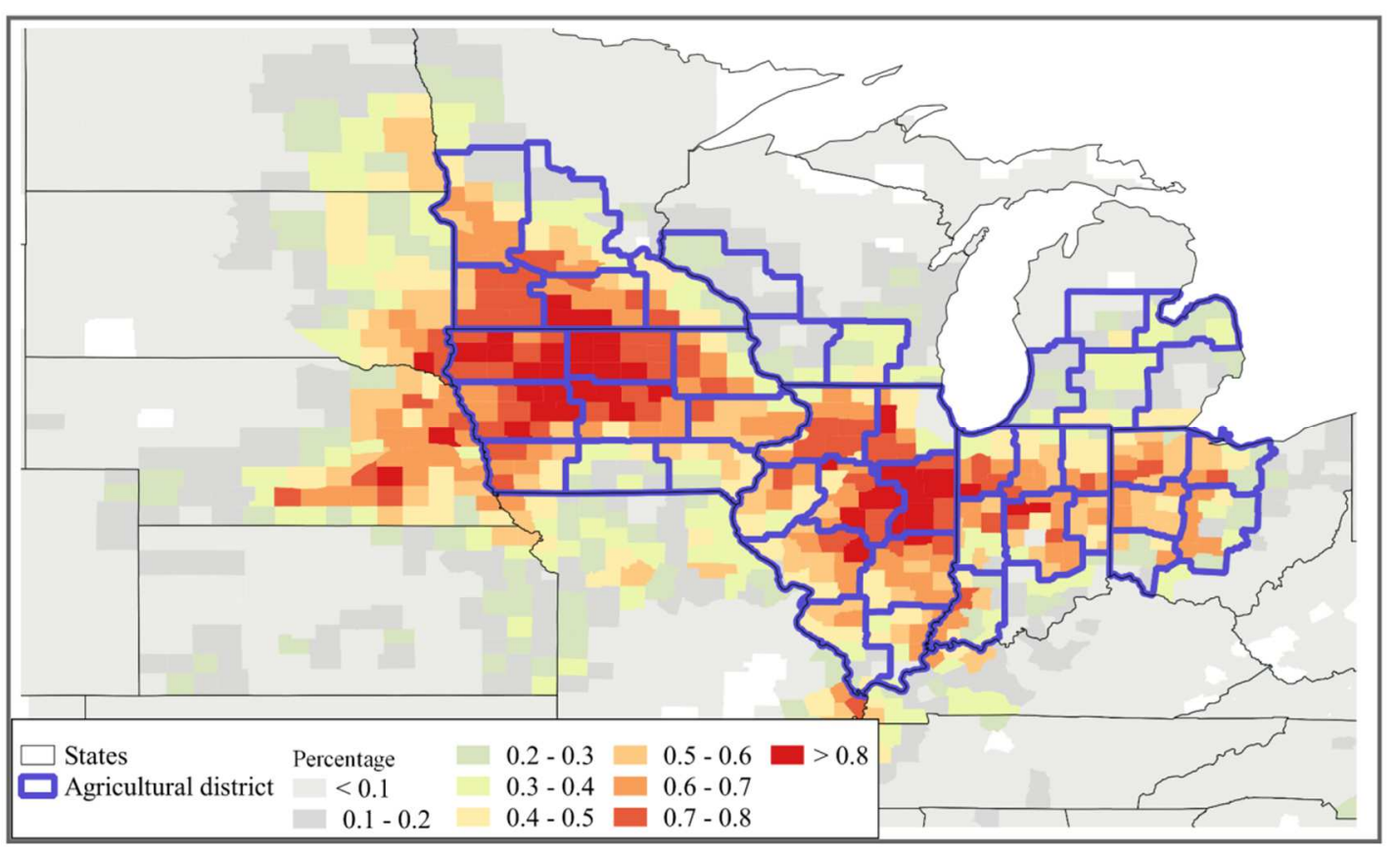

Figure 1. Study area outlined by the blue boundary, with the background showing the average proportion of corn and soybean planting area in the total area based on United States Department of Agriculture (USDA) survey data in 1997, 2002, 2007 and 2012.

\subsection{Crop yield dataset}

The agricultural district level crop yield for corn and soybean in the study area during 2003 to 2014 was collected from the USDA National Agricultural Statistics Service (NASS). In this study, NASS reported crop yields not designated as irrigated or non-irrigated conditions were treated as non-irrigated. The annual anomalies of crop yield were calculated for each agricultural district by subtracting a linear yield trend fitted for each district from the actual yield (Li et al., 2019; Lu et al., 2017; Zipper et al., 2016).

\subsection{Observation-based hydrological cycle components}

We used a set of observations of the individual hydrological cycle components to assess their 
relationship with crop yield:

$$
\mathrm{P}=\mathrm{ET}+\Delta \mathrm{S}+\mathrm{Q}
$$

The observation-based hydrological cycle components used in this study were obtained from the following sources.

Precipitation (P): Since the station-based precipitation (i.e., Precipitation Regression on Independent Slopes Model (PRISM)) is highly consistent with the precipitation of the North American Land Data Assimilation System (NLDAS) at the agricultural district scale in the study area, the NLDAS precipitation was used as the observation-based precipitation to simplify the analysis process.

Evapotranspiration (ET): Breathing Earth System Simulator (BESS ET).

Subsurface water storage change $(\Delta \mathbf{S})$ : Total terrestrial water storage (TWS) retrieved by the Gravity Recovery and Climate Experiment (GRACE).

Soil moisture: European Space Agency (ESA) climate change initiative (CCI) surface soil moisture (CCI SSM).

Streamflow (Q): Discharge data from the United States Geological Survey (USGS Q).

Detailed information about these data are given in the following sections.

\subsubsection{Evapotranspiration from the Breathing Earth System Simulator (BESS)}

BESS is a satellite-driven water-carbon-energy coupled biophysical model (Jiang and Ryu, 2016; Ryu et al., 2011). By using MODIS aerosol, cloud and atmospheric profile products, BESS calculates solar radiation (Ryu et al., 2018), air temperature and humidity to drive the land surface process modules. Using MODIS LAI, albedo and clumping products, BESS quantifies the solar radiation absorption by the sunlit/shaded canopy through the explicit computation of direct/diffuse radiation in the atmosphere and canopy (Ryu et al., 2011). With these environmental and vegetation inputs, BESS computes ET from the sunlit/shade canopy by solving a quadratic Penman-Monteith equation through an iterative procedure, in which ET estimates are constrained by both energy absorption and carbon uptake (Jiang and Ryu, 2016; Ryu et al., 2011). PET is further calculated using the Priestley-Taylor equation. The 
214 global BESS ET product was evaluated against a global network of eddy-covariance tower

215 observations and against global coarse-resolution maps upscaled using machine learning

216 (Jiang and Ryu, 2016; Jiang et al., 2020). BESS monthly ET and PET between 2003 and 2014

217 were used in this study.

$218 \quad$ 2.3.2 Total terrestrial water storage (TWS) from GRACE

219 The GRACE-derived TWS anomaly captures bulk land water storage changes, including 220 contributions from surface water, soil moisture, and deeper groundwater storages. TWS is retrieved from the gravimetric sensor derived water mass variations (Landerer and Swenson, 2012). The GRACE TWS product used here is the Monthly Mass Grids - Land product with $1^{\circ}$ spatial resolution, where each grid value represents the surface mass deviation from the baseline averaged from January 2004 to December 2009. There are three available GRACE TWS products, which are developed by the Center for Space Research at the University of Texas, Austin (CSR), NASA Jet Propulsion Laboratory (JPL) and GeoforschungsZentrum Potsdam (GFZ), respectively. To reduce the noise from different gravity field solutions (Sakumura et al., 2014), the average value of these three products was used in our analysis.

\subsubsection{Surface soil moisture (SSM) from ESA CCI}

230 The ESA CCI soil moisture project is part of the ESA Programme on Global Monitoring of 231 Essential Climate Variables (ECV), which produces surface soil moisture products by 232 combining observations from multiple active and passive microwave satellite sensors launched after 1979 (Gruber et al., 2019, 2017; Dorigo et al., 2017). Microwave remote sensing has been proven effective to estimate surface soil moisture content, as there is a significant difference in the dielectric properties between soil and liquid water (Njoku and

236 Entekhabi, 1996). However, depending on the sensor configurations (i.e. wavelength, incident 237 angle etc.) and surface condition (i.e. vegetation cover, soil moisture content, roughness etc.), 238 the effective penetration depth of the microwave signal usually ranges from 0 to $5 \mathrm{~cm}$ (Peng et al, 2017). Therefore, the microwave-based soil moisture observations predominantly reflect surface soil conditions rather than deeper root zone soil moisture which is more directly 
accessible to plants (Njoku et al., 2003; Wigneron et al., 2017). We use the CCI surface soil moisture (CCI SSM) product between 2003 and 2014, which is daily and has a $25 \mathrm{~km}$ spatial resolution. For this period, the Advanced Microwave Scanning Radiometer on the Earth Observing System Aqua satellite (AMSR-E) (Njoku et al., 2003) and the Advanced Scatterometer (ASCAT) on the Meteorological Operational satellite A (MetOp-A) (Hollmann et al., 2013) are the major passive and active sensors used for soil moisture retrievals. The monthly CCI-SSM was obtained by aggregating the daily product.

\subsubsection{Discharge data from USGS}

The observed (2003-2014) monthly runoff data for all the hydrologic unit code level 8 (HUC8) catchments within the study domain were obtained from the USGS WaterWatch system (Jian et al., 2008). This dataset provides computed runoff for individual HUCs, which were generated by combining historical flow data collected at streamgages, the drainage basins of the streamgages, and the boundaries of the HUCs. The HUC-8 level runoff was rasterized and aggregated to the agricultural district scale for our analysis.

\subsection{Model-simulated hydrological cycle components}

We used the simulated monthly hydrological cycle components from the NLDAS-Noah model outputs as the model-simulated hydrological cycle components. NLDAS Phase 1 (NLDAS-1) (Mitchell, 2004) was initiated in 1999, sponsored by the Global Energy and Water Cycle Experiment (GEWEX) Continental-Scale International Project (GCIP) covering the continental United States, southern Canada, and northern Mexico. Four land-surface models (LSMs) including Noah, Variable Infiltration Capacity (VIC), Sacramento Soil Moisture Accounting (SAC-SMA), and Mosaic are executed in parallel and uncoupled in NLDAS in both real time and retrospective modes. By assimilating the meteorological forcing, and soil and vegetation parameters, NLDAS produces quality-controlled long-term and near real-time products to support national operational drought monitoring and prediction, and to provide water resource information needed by various government agencies, academia, and other enterprises. As an update of NLDAS-1, the NLDAS Phase 2 
(NLDAS-2, Xia et al., 2012a, 2012b) extended the study time window from 3 years (19971999) to 30 years (1979-2008), using more accurate and consistent surface forcing data (including both station gauged meteorological data and North American Regional Reanalysis (NARR) atmospheric forcing data), and upgrading the land-surface model code and parameters. The spatial resolution of NLDAS output is $0.125^{\circ}$ with hourly intervals. In this study, NLDAS2-Noah monthly outputs (aggregated from hourly outputs) between 2003 and 2014 were used. The following NLDAS2-Noah model-simulated hydrological cycle components were used in our analysis:

$\mathrm{P}$ (NLDAS P): Summing the liquid precipitation (ARAIN) and frozen precipitation (ASNOW) components;

ET (NLDAS ET): Total evapotranspiration;

$\Delta \mathrm{S}$ (NLDAS $\Delta \mathrm{S})$ : Change of model subsurface $(0-200 \mathrm{~cm}$ depth) soil moisture content; SMC_10 cm (NLDAS SMC_10 $\mathrm{cm})$ : model subsurface $(0-10 \mathrm{~cm}$ depth) soil moisture content; SMC_200cm (NLDAS SMC_200cm): model subsurface $(0-200 \mathrm{~cm}$ depth) soil moisture content;

Q (NLDAS Q): Sum of the subsurface runoff (BGRUN) and surface runoff (SSRUN) components.

\subsection{Drought indices}

Besides the hydrological cycle components, several commonly used drought indices were also adopted to analyze the relationship between drought indices and crop yield. Here we chose four widely used drought indices, including VPD, fET, SPEI, and PDSI. A summary of the drought indices and their sources is provided below.

\subsubsection{PRISM vapor pressure deficit product}

The VPD is the difference between the water vapor pressure in the air and the saturated water vapor pressure at the same air temperature. VPD indicates the atmospheric dryness and has been found to affect crop yield of corn and soybean by limiting stomatal opening and also depleting soil moisture (Lobell et al., 2014). Here, we use VPD as a measure of atmospheric 
drought or dryness (Anderson, 1936). The VPD product used here is the gridded monthly maximum VPD from the PRISM with time period between 2003 and 2014. PRISM provides a suite of gridded high accuracy climate variables across the continental U.S. (Daly et al., 2008). It is based on the quality-controlled measurements from the U.S. weather station network, and generates gridded product by conducting a climate-elevation regression for each digital elevation model (DEM) grid cell considering the location, elevation, coastal proximity, aspect, vertical atmospheric layer, topographic position, and orographic effectiveness of the terrain (Daly et al., 2008).

\subsection{2 fET}

fET is the ratio of actual ET to PET, which describes the difference between the crop water demand and water supply. The anomaly of fET has been widely used for drought monitoring (Anderson et al., 2016b; Otkin et al., 2013) and crop yield estimation (Anderson et al., 2016a; Yang et al., 2018). The fET used here was calculated based on the BESS monthly ET and PET products between 2003 and 2014.

\subsubsection{SPEI}

The SPEI is a variate of the SPI, taking both precipitation and evapotranspiration into account (Beguería et al., 2014; Vicente-Serrano et al., 2010). The SPEI used here was acquired from the National Center for Atmospheric Research (NCAR) (Vicente-Serrano, 2015), which uses the FAO-56 Penman-Monteith method to estimate potential evapotranspiration. This dataset covers the period between 1901 and 2015 with $0.5^{\circ}$ spatial resolution and monthly fidelity. The SPEI record used here spans the period between 2003 and 2014.

\subsubsection{PDSI}

The PDSI quantifies the relative dryness by incorporating antecedent and current moisture supply (P) and demand (PET) into a hydrological accounting system, and using a 2-layer bucket-type model to calculate the soil moisture (Dai et al., 2004; Wayne, 1965; Wells et al., 2004). The PDSI is the most commonly used drought index (Vicente-Serrano et al., 2010), although there have been several criticisms on its limitations (Alley, 1984; Dai, 2011; 
Sheffield et al., 2012). The monthly self-calibrating PDSI during 2003 and 2014 was also downloaded from NCAR (Dai, 2019) with a spatial resolution of $2.5^{\circ}$.

\subsection{Methods}

We conducted three major analyses. The first analysis was to understand the relationship and its spatio-temporal dynamics between crop yield and the hydrological cycle components and drought indices. Specifically, anomaly correlation (Pearson's correlation) coefficients between crop yield and hydrological cycle components and drought indices were calculated for each month during the growing season (April to October), to assess the impact of different hydrological variables on crop yield and how the relationships vary in time and space. The second analysis was a case study to understand how the different hydrological variables evolved during the intense 2012 drought. Specifically, we analyzed the temporal evolutions of both monthly normalized (using maximum-minimum normalization method based on the data from 2003 to 2014) hydrological cycle components and drought indices in 2012, and used the corresponding percentile values of 2012 for the analysis based on all data from 2003 to 2014 . By doing so, we were able to study the potential mechanisms leading to crop stress and yield loss. The third analysis was to integrate the hydrological variables together to assess the capability for predicting crop yield purely based on hydrological variables. Specifically, we used an advanced regression method, Partial Least Square Regression (PLSR), to explore the seasonal crop yield predictability by combining the different hydrological cycle components and associated drought indices, and to further interpret the shared and unique values of the different hydrological variables in terms of their contributions to predict crop yield and quantify the impact of agricultural drought.

\subsubsection{Relationship between hydrological cycle components and crop yield}

All observation-based and model-simulated hydrological cycle components, and drought indices were aggregated to the agricultural district scale using the mean value of the pixels contained in each agricultural district. The anomalies of hydrological cycle components and drought indices were calculated by subtracting the monthly multi-year mean value of each 
agricultural district. The anomaly correlation coefficients $(\boldsymbol{r})$ between the crop yield and different hydrological variables were calculated to qualify the relationship between crop yield and hydrological cycle components or drought indices. The overall correlation coefficients were calculated for each month using all available data for all agricultural districts. The correlation coefficients for each month and each agriculture district were also calculated to understand the spatial and temporal evolution of the relationship between crop yield and hydrological cycle components or drought indices.

\subsubsection{Evaluation of the extreme drought year 2012}

We used the 2012 drought as a case study to further understand how different hydrological variables evolved in an extreme drought year. The monthly normalized hydrological cycle components and drought indices in 2012 were analyzed in terms of their percentile value based on the whole study period (i.e. 2003-2014), instead of their absolute values. Analyzing the monthly data can reveal time lags of the different hydrological variables, and potentially provide insights on the underlying mechanisms of the 2012 drought affecting crop growth.

\subsubsection{PLSR and seasonal prediction of crop yield}

We used PLSR to integrate the different hydrological cycle components and drought indices for crop yield prediction, and to inform the potential development of a new drought index. PLSR is a regression method similar to principal components regression (PCR), which projects both independent and dependent variables into the variable space (i.e. latent variables) through the linear combination of the original variables (Guan et al., 2017). The latent variables are obtained to maximize the covariance between the latent variables that are derived from the dependent variables and the latent variables that are derived from the independent variables. Compared to PCR and multiple linear regression, the performance of PLSR is more robust (Geladi and Kowalski, 1986).

The observation-based hydrological cycle components (NLDAS P, USGS Q, CCI SSM, GRACE $\triangle \mathrm{S}$, BESS ET), fET and VPD were used as independent variables in the PLSR. We 
used the observation-based hydrological cycle components, instead of the model-simulated ones, as they show similar performance in capturing the yield variabilities (i..e Figure 2) and the observation-based ones may have less uncertainties. fET and VPD were chosen to be independent variables in the PLSR as they show better performance relative to the other drought indices in depicting yield variabilities (i.e. Figure 2). PLSR models were developed separately for corn and soybean because these crop types show different yield responses to variations in the hydrological variables (i.e. Figure 2). The hydrological cycle components and drought indices for each month and all months prior since May of each calendar year of the study period were used to test the seasonal predictability of the first component and optimal (model with the minimum cross-validation root-mean-square error (RMSE) during model training) PLSR models. We conducted a 100-fold bootstrap process for the crop yield predictions using the combination of the hydrological cycle components and drought indices; and for each bootstrap, $80 \%$ of the data were selected randomly for model training, and the remaining $20 \%$ for model validation. The mean value and standard deviation of RMSE and $\mathrm{R}^{2}$ (coefficient of determination) of each combination were calculated based on the bootstrap results.

Table 1. Description of the datasets used in this study

\begin{tabular}{|c|c|c|c|c|}
\hline Categories & Dataset & $\begin{array}{c}\text { Original dataset } \\
\text { time period }\end{array}$ & $\begin{array}{c}\text { Spatial } \\
\text { Resolution }\end{array}$ & Reference \\
\hline Observation- & $\begin{array}{l}\text { BESS ET } \\
\text { BESS PET }\end{array}$ & $2002-2017$ & $5 \mathrm{~km}$ & $\begin{array}{c}\text { (Jiang and Ryu, } \\
\text { 2016) }\end{array}$ \\
\hline $\begin{array}{l}\text { based } \\
\text { hydrological }\end{array}$ & GRACE $\Delta S$ & $2002-2017$ & $1^{\circ}$ & $\begin{array}{c}\text { (Landerer and } \\
\text { Swenson, 2012) }\end{array}$ \\
\hline $\begin{array}{l}\text { cycle } \\
\text { components }\end{array}$ & $\begin{array}{l}\text { CCI SSM } \\
\text { USGS Q }\end{array}$ & $\begin{array}{l}1978-2016 \\
1900-2016\end{array}$ & $\begin{array}{c}25 \mathrm{~km} \\
\text { HUC level } 8\end{array}$ & $\begin{array}{c}\text { (Dorigo et al., 2017) } \\
\text { (Jian et al., 2008) }\end{array}$ \\
\hline $\begin{array}{c}\text { Model- } \\
\text { simulated }\end{array}$ & $\begin{array}{c}\text { NLDAS- } \\
\text { Noah's P, ET, }\end{array}$ & 1979-2019 & $0.125^{\circ}$ & $\begin{array}{l}\text { (Mitchell, 2004; Xia } \\
\text { et al., 2012b, 2012a) }\end{array}$ \\
\hline
\end{tabular}




\begin{tabular}{ccccc}
\hline $\begin{array}{c}\text { hydrological } \\
\text { cycle } \\
\text { components }\end{array}$ & PET, & & & \\
& SMC_200cm, & & & \\
and Q & & & \\
\hline & PRISM VPD & $1895-2019$ & $5 \mathrm{~km}$ & (Daly et al., 2008) \\
Commonly & BESS fET & $2002-2017$ & $5 \mathrm{~km}$ & (Jiang and Ryu, \\
used drought & & & & 2016) \\
indices & SPEI & $1901-2015$ & $0.5^{\circ}$ & (Vicente-Serrano, \\
& & & & 2015) \\
& PDSI & $1850-2014$ & $2.5^{\circ}$ & (Dai, 2019) \\
\hline
\end{tabular}

\section{Results}

\subsection{Correlations between hydrological cycle components and crop yield}

Our results show that crop growth and yield are sensitive to the variability of the hydrological cycle, and that water stress during different growth stages can lead to distinctive impacts on the end-of-season crop yield (Çakir, 2004; Mladenova et al., 2017). The anomaly correlation between crop yield and different hydrological variables (i.e. observation-based and modelsimulated hydrological cycle components, and drought indices) for the different months are shown in Figure 2. Specifically, we find that almost all anomaly correlation coefficients have similar seasonal patterns, i.e. the maximum absolute value of $\boldsymbol{r}(|\boldsymbol{r}|)$ between the hydrological variables and crop yield appears in July or August for corn, and in August or September for soybean. This seasonal pattern is consistent with the key growth stages of corn and soybean in the rainfed part of the U.S. Corn Belt, where July and August coincide with the flowering and major grain-filling stages for corn; soybean, in contrast, is usually planted after corn and has 406 later critical flowering and pod filling stages (i.e. in August and September) (Guan et al., 2017). 
Corn yield, in general, has a higher correlation with different hydrological variables and

410 drought indices than soybean yield, and both observation-based and model-simulated

411 hydrological cycle components show such a pattern (Figure 2). This result indicates higher

412 sensitivity of corn yield to water stress than soybean, consistent with prior work (Lobell et al.,

413 2014). The apparent lower soybean yield sensitivity to water stress may be because soybean

414 has a better ability to regulate growth rates during unfavorable environmental conditions

415 compared to corn (Boyer, 1970; Huck et al., 1983; Turner and Begg, 1981). Among all the

416 observation-based hydrological variables (Figure 2 a, d), CCI SSM shows the highest

417 correlation magnitude (i.e. $|\boldsymbol{r}|$ ) with crop yield for both corn and soybean, though the peak

418 correlations happen at different times (July for corn and August for soybean). Besides CCI

419 SSM, GRACE $\triangle \mathrm{S}$ also shows a high correlation with corn yield, although much less so for

420 soybean. This is reasonable as SSM and $\Delta \mathrm{S}$ are correlated with each other in the rainfed

421 region of the U.S. Corn Belt due to limited groundwater pumping in this region. For corn,

422 BESS ET also has a comparable yield sensitivity in August and September, as well as BESS

423 PET in June and July. As for soybean, BESS ET in June, and NLDAS P and CCI SSM in

424 August had higher correspondence to crop yield compared with other observation-based

425 hydrological cycle components.

Regarding the correlation $|\boldsymbol{r}|$ between anomalies of different drought indices and crop yield, VPD and fET show the highest $|\boldsymbol{r}|$ for both corn and soybean, although the peak times are different for each crop type. For corn, the correlation of VPD with yield peaks in July, which is one month earlier than fET (peak in August), although the peak $|r|$ of VPD with yield is slightly lower than that of fET. A reversed pattern is found for soybean, i.e. $|\boldsymbol{r}|$ of fET peaks in June, which is two months earlier than $|r|$ of VPD, though the peak $|r|$ of fET is slightly lower than that of VPD. In addition, for corn, VPD has a larger $|\boldsymbol{r}|$ than other drought indices for the months following May, and the peak $|\boldsymbol{r}|$ of VPD is one month earlier than other drought indices except for the SPEI. While for soybean, $|\boldsymbol{r}|$ of fET is significantly larger than the other 
indices in June and July, while the peak $|\boldsymbol{r}|$ for fET occurs two months ahead of the other drought indices. The above results suggest that VPD and fET may provide effective early warning indicators for corn and soybean yield loss, respectively.
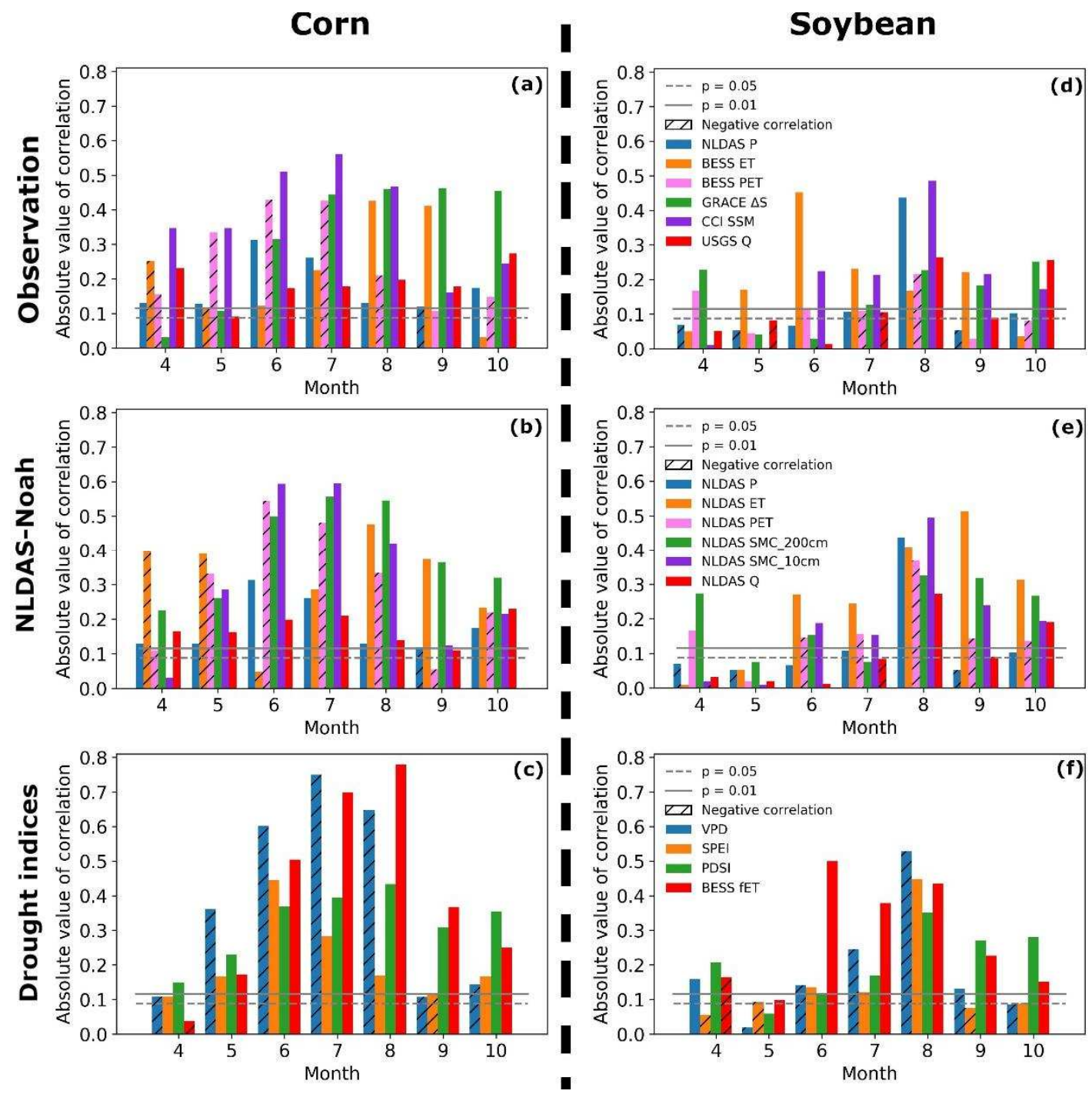

Figure 2. The anomaly correlation between hydrological cycle components or drought indices and corn or soybean yield.

3.2 Spatio-temporal evolution of the relationship between hydrological variables and crop yield

445 Anomaly correlation between the hydrological variables and crop yields vary in both space 446 and time over the rainfed part of the U.S. Corn Belt (Figure 3). For Figure 3, we selected five hydrological variables (NLDAS P, CCI SSM, BESS ET, fET, and VPD) based on their $|\boldsymbol{r}|$ 
rankings in Figure 2; the patterns of the other hydrological variables are shown in Figures S1-

S3. Specifically, most hydrological variables showed a similar spatio-temporal evolution, i.e. their $\boldsymbol{r}$ reaches a (spatially homogeneous) maximum (i.e. for CCI SSM, BESS ET, and fET) or minimum (i.e. for VPD) during June to August. For corn, during June to August, the $\boldsymbol{r}$ of VPD is negative homogeneously in space, while the $\boldsymbol{r}$ values for fET and CCI SSM are positive homogeneously in space. The $\boldsymbol{r}$ pattern for soybean shows a similar spatio-temporal of the hydrological variables show large spatial heterogeneity for both corn and soybean.

Considering the absolute value $(|\boldsymbol{r}|)$ and spatial distribution (e.g. degree of spatial homogeneity) of $\boldsymbol{r}$, some hydrological variables show potential value as early warning indicators of crop yield loss. For corn, VPD and CCI SSM in May start to show spatially homogeneous correlation patterns with annual yield, while the pattern strengthens over subsequent months and reaches a peak in August, especially over the southern rainfed portion of the Corn Belt (Figure 3). The corn yield predictability of VPD and CCI SSM in May is explained by the temporal evolution of their correlation with crop yield (Figure 3), which both show relatively stronger but similar correlation patterns with crop yield in the following critical summer months (i.e. June, July, and August). While for soybean, BESS ET and fET in June start to show a more homogeneous correlation pattern in space, but with increasing heterogeneity in the correlation pattern beginning in July. These earlier warning indicators are consistent with the overall correlation pattern between anomalies in crop yield and hydrological variables (Figure 2). 


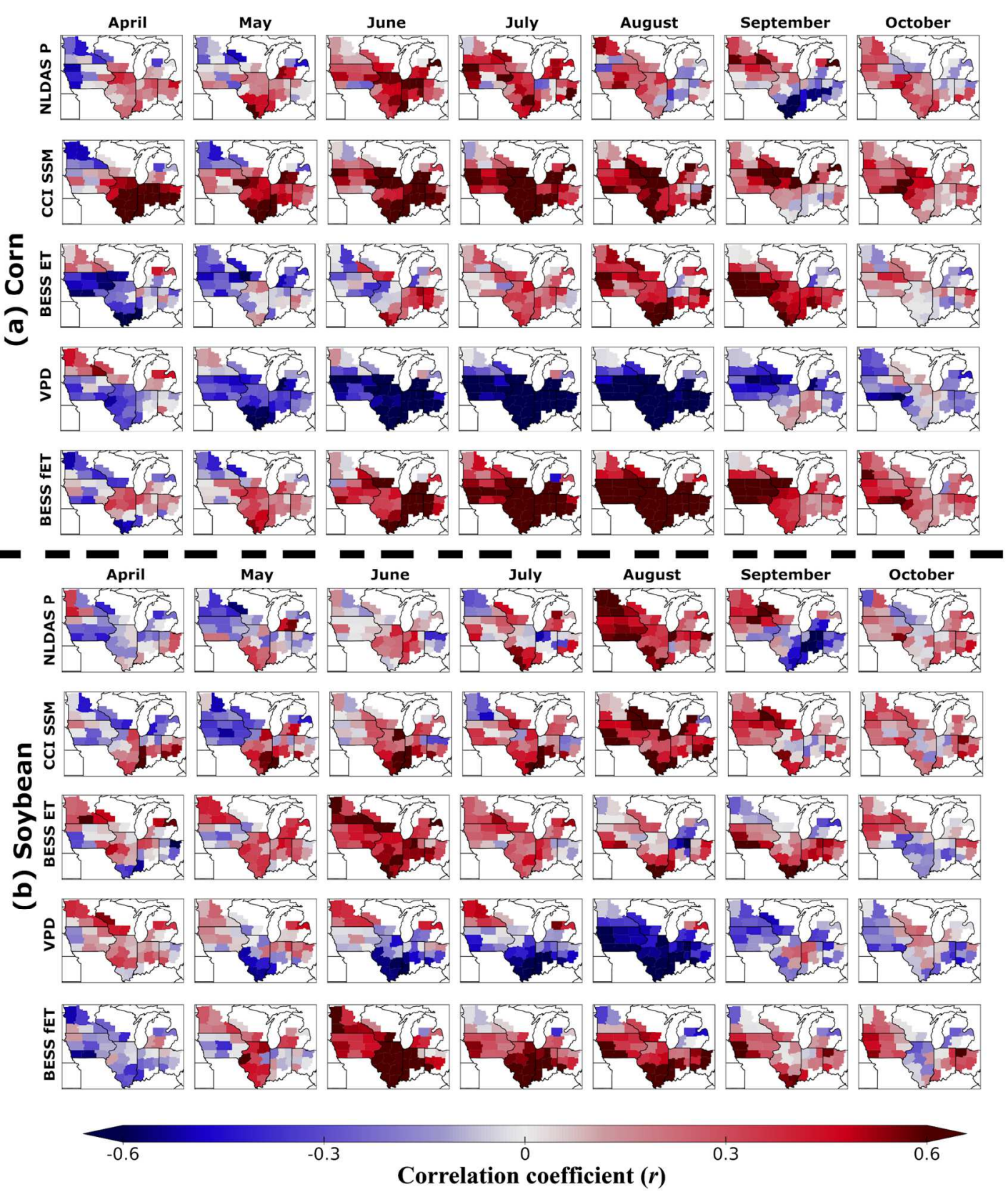

473 Figure 3. Correlation patterns between monthly hydrological components and crop yield for rainfed corn and soybean crop types.

\section{$475 \quad 3.3$ Evaluation of the extreme drought year 2012}

476 The 2012 drought was one of the most severe droughts occurred in the U.S. Midwest and

477 Central Great Plains over the past century, causing large crop yield losses for both corn and soybean (Mallya et al., 2013). Our results confirm that the 2012 drought led to severe yield

479 loss in the rainfed Corn Belt, and the associated drought signal was clearly evident in the 
growing season averaged selected hydrological variables from 2003 to 2014 (Figure 4).

481 Figure 4 shows that the detrended corn yield in 2012 was at its lowest value for the study period. The detrended soybean yield was also anomalously low in 2012 and second only to 2003, which had the lowest recorded soybean yield for the study period due to crop disease (Wrather and Koenning, 2006). In 2012, some hydrological cycle components and all of the drought indices showed extremely low values compared to the other years between 2003 and 2014. Specifically, both observation-based and model-simulated P, Q, SM, $\Delta$ S in 2012 reached their historical minimums during the study period, but not for ET and PET. PET had its maximum value in 2012, consistent with an exacerbated moisture deficit during the drought year. The observation-based ET reached its lowest value in 2012, consistent with minimal moisture levels available for evaporation. In contrast, the NLDAS model simulated ET was actually normal in 2012, which may be due to model uncertainties in simulating ET in such an extreme year.
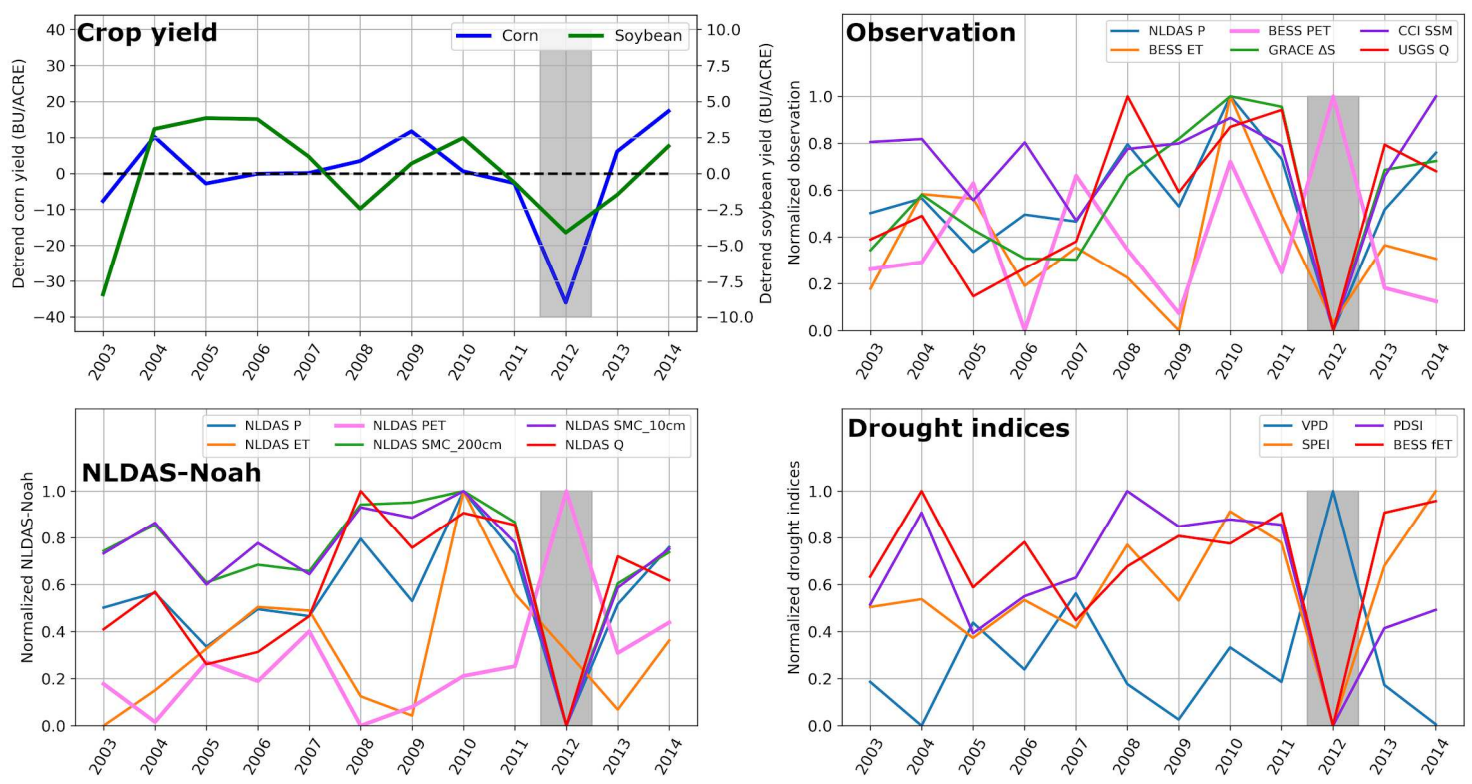

Figure 4. Detrended crop yields for corn and soybean, normalized hydrological cycle components, and normalized drought indices from 2003 to 2014. The normalized hydrological cycle components and drought indices were calculated using the min-max normalization method based on the growing season (from April to September) averaged data from 2003 to 2014. 
500 The seasonal patterns of the different hydrological variables in 2012 are shown in Figure 5, 501 and benchmarked with percentile values calculated from all of the years between 2003 and 2014. $\mathrm{P}$ in 2012 was near normal in the beginning of this year, but became abnormally low in June and July as drier conditions emerged. ET and PET were both very high from January to May in 2012, primarily due to the high VPD (i.e. high atmospheric water demands) and sufficient soil moisture (i.e. sufficient water supply); but then ET started to significantly decline after May and reached its lowest value in August and September, while PET only had a slight decrease in the following months. This ET decrease was primarily due to the dramatic depletion of soil moisture by the high ET rates that occurred from January to May, and the lack of precipitation during summer. This drawdown of soil moisture in early 2012 is confirmed by both CCI SSM (showing a sharp decrease from March to April and remaining historically low until September) and GRACE $\Delta \mathrm{S}$ (showing a more gradual decrease, but

512 continuing at low levels from June to December). Notably, Q also reached its lowest level in 513 April, which continued afterwards until December in 2012. After the crop growth season, ET 514 and CCI SSM increased after September due to the recovery of precipitation, while GRACE $515 \Delta \mathrm{S}$ and USGS Q remained near minimum levels, indicating the time latency to recover severe 516 groundwater depletion. A similar result is also found from the evolution of the modelsimulated water components (Figure 6). 

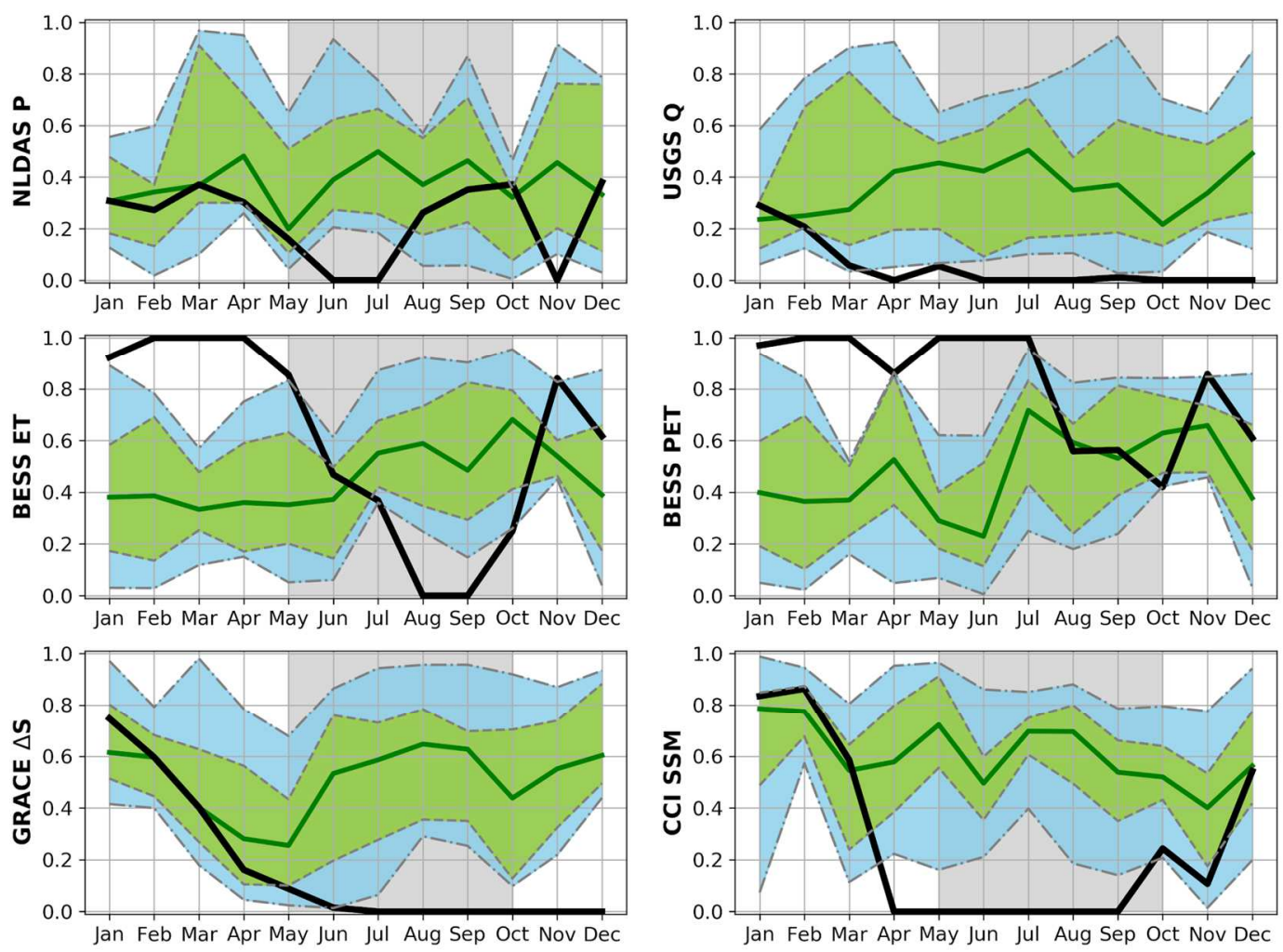

Extreme year 2012 $50 \%$ percentile

519 Figure 5. Comparison of the normalized water components in 2012 with observation-based percentiles calculated using all of the data from 2003 to 2014 . The monthly normalized observation-based hydrological cycle components were calculated using the max-min normalization method based on monthly data from 2003 to 2014. The black line indicates the seasonal cycle of the normalized observation-based hydrological cycle components in 2012. The dark green curve indicates the $50 \%$ percentiles, the blue shade indicates the upper and lower $10 \%$ ranges, and the light green shade indicates the upper and lower $25 \%$ ranges of monthly normalized observation-based hydrological cycle components, respectively. 

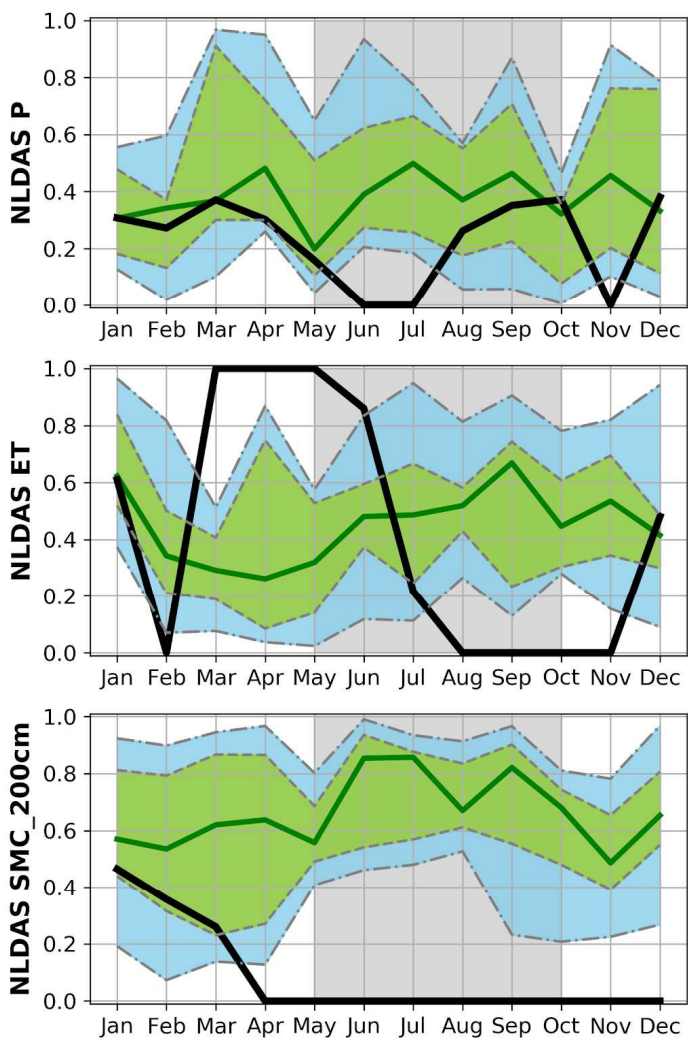

Extreme year 2012 $50 \%$ percentile
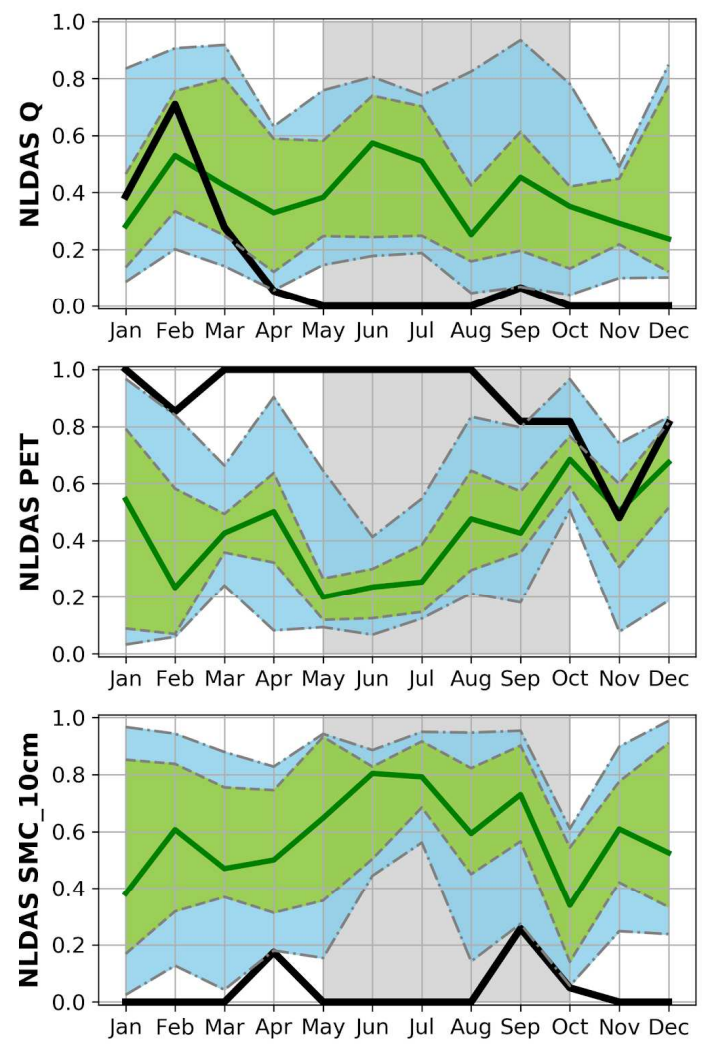

Upper and lower 10\%

Upper and lower 25\%

Figure 6. Comparison of the normalized water components in 2012 with the normalized model-simulated percentiles calculated using all of the data from 2003 to 2014 . The monthly normalized model-simulated hydrological cycle components were calculated using the maxmin normalization method based on monthly NLDAS-Noah data from 2003 to 2014. The black line indicates the seasonal cycle of normalized model-simulated hydrological cycle components in 2012. The dark green curve indicates the 50\% percentiles, the blue shade indicates the upper and lower 10\% ranges, and light green shade indicates the upper and lower $25 \%$ ranges of monthly normalized model-simulated hydrological cycle components, respectively.

We further investigate how well the drought indices captured the seasonal evolution of the

5412012 drought (Figure 7). Generally, the drought indices detect different duration and peak

542 time for the 2012 drought. However, all of the drought indices indicate the historically severe 543 drought event in June and July. In 2012, VPD was historically the highest before September 
544 (except for April) during the study period. The SPEI shows a similar seasonal cycle as 545 NLDAS P in 2012, and reaches its lowest value in June and July, within the critical growing 546 stages of corn and soybean. The PDSI reaches its lowest value in May and remains low until 547 December in 2012, while fET reaches its lowest value from March to September (except for 548 April) in 2012.
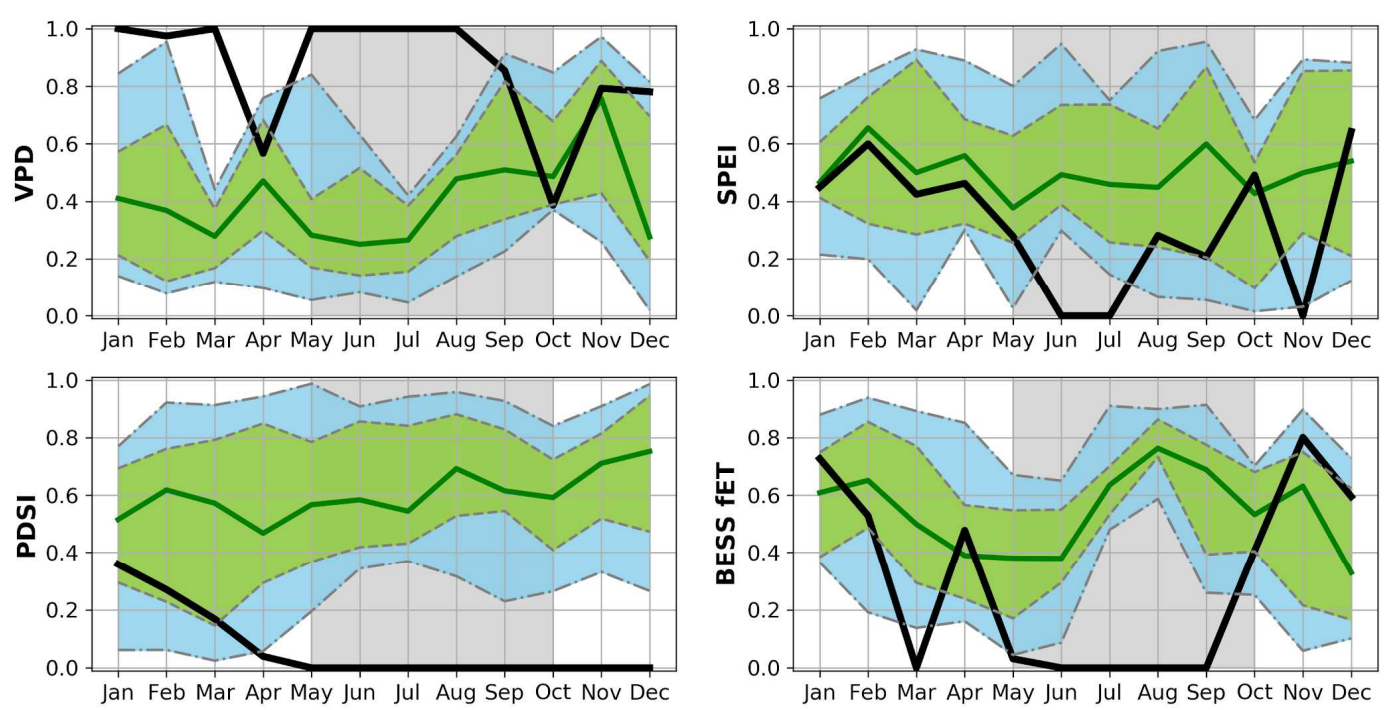

Upper and lower $10 \%$

Upper and lower $25 \%$

Figure 7. Comparison of the normalized drought indices in 2012 with the percentiles calculated using all of the data from 2003 to 2014. The monthly normalized drought indices were calculated using the max-min normalization method based on monthly data from 2003 to 2014. The black line indicates the seasonal cycle of normalized drought indices in 2012. The dark green curve indicates the $50 \%$ percentiles, the blue shade indicates the upper and lower $10 \%$ ranges, and the light green shade indicates the upper and lower $25 \%$ ranges of monthly normalized drought indices, respectively. 

indices
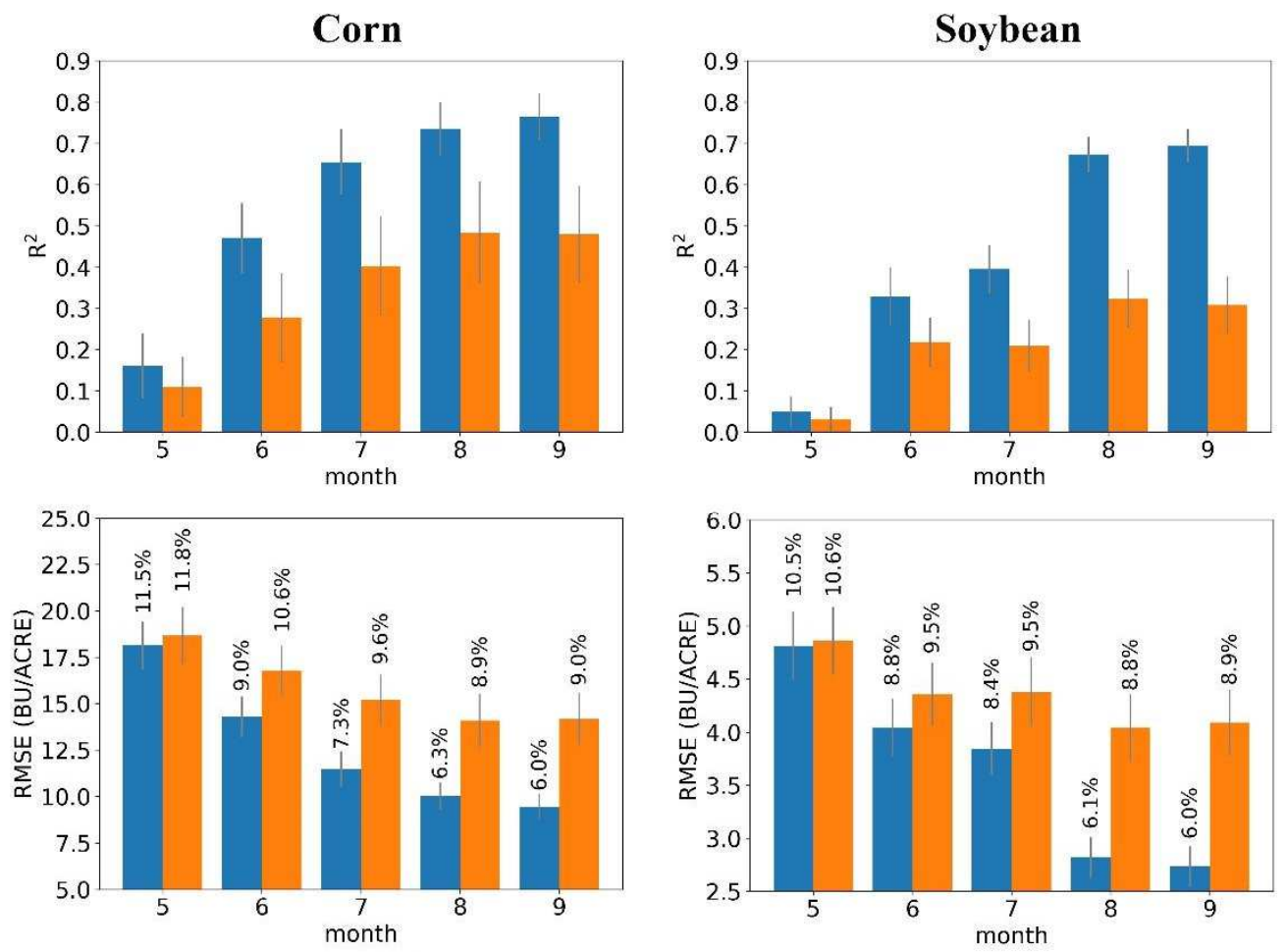

Figure 8. The performance of crop yield predictability using the PLSR optimal model and the

PLSR first-component model. The performance in each month represents the model prediction skill when ingesting data from May until the end of each given month. The filled and error bars represent the respective means and standard deviations based on 100-time bootstrapping. In each bootstrap, $80 \%$ of the data (hydrological information of current month and before) was used for model training, and the remaining $20 \%$ of the data for model validation. The percentages listed above the bars of the RMSE subplots are the normalized RMSE values (RMSE divided by multi-year averaged crop yield).

Accurate seasonal forecasts of end-of-season crop yield are important for early warning of 
food insecurity, supply chain planning for the agriculture industry, and market prediction (Peng et al., 2018b; Peng et al., 2020b). The effective use of combined information from multiple hydrological variables has the potential to improve crop yield prediction. Here we use PLSR to explore the value of integrating different hydrological variables and their seasonal information for corn and soybean yield prediction. Overall, corn yield can be predicted better than soybean yield based on the combination of hydrological variables for both the PLSR optimal model and PLSR first-component model (Figure 8). For corn, the $\mathrm{R}^{2}$ of the two models are 0.76 and 0.47 when benchmarked with the NASS yield statistics, and the normalized RMSEs of the two models are $6.0 \%$ and $9.0 \%$ at the end of growing season, respectively. For soybean, the $\mathrm{R}^{2}$ of the two models are 0.70 and 0.31 , and the normalized RMSEs are $6.0 \%$ and $8.9 \%$ at the end of the growing season, respectively. The PLSR performance is improved when more seasonal hydrological information is ingested into the model, and this improvement in model performance can be largely explained by the observed relationships between crop yield and the seasonal hydrological variables (i.e. Figure 2). For corn, adding hydrological information of June and July most significantly improves the crop yield prediction accuracy ( $\mathrm{R}^{2}$ improved from 0.16 to 0.47 for June, and from 0.47 to 0.65 for July). For soybean, adding hydrological information of June and August can most significantly improve soybean yield prediction accuracy (R2 improved from 0.05 to 0.33 for June, and R2 from 0.40 to 0.67 for August) . 

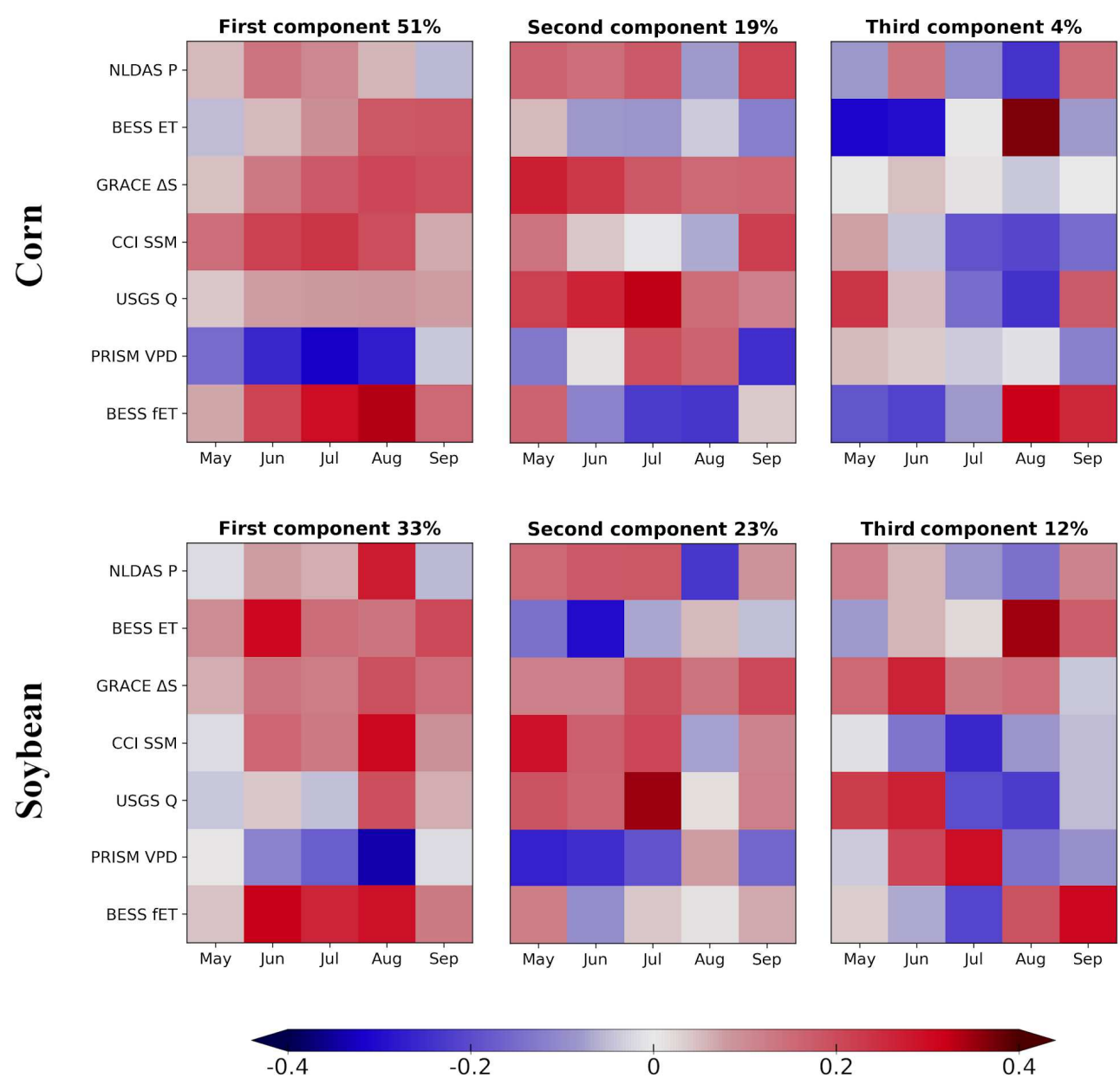

$-0.2$

0.2

0.4

601 Figure 9. The loading of the first three components of the optimal PLSR crop yield model in 

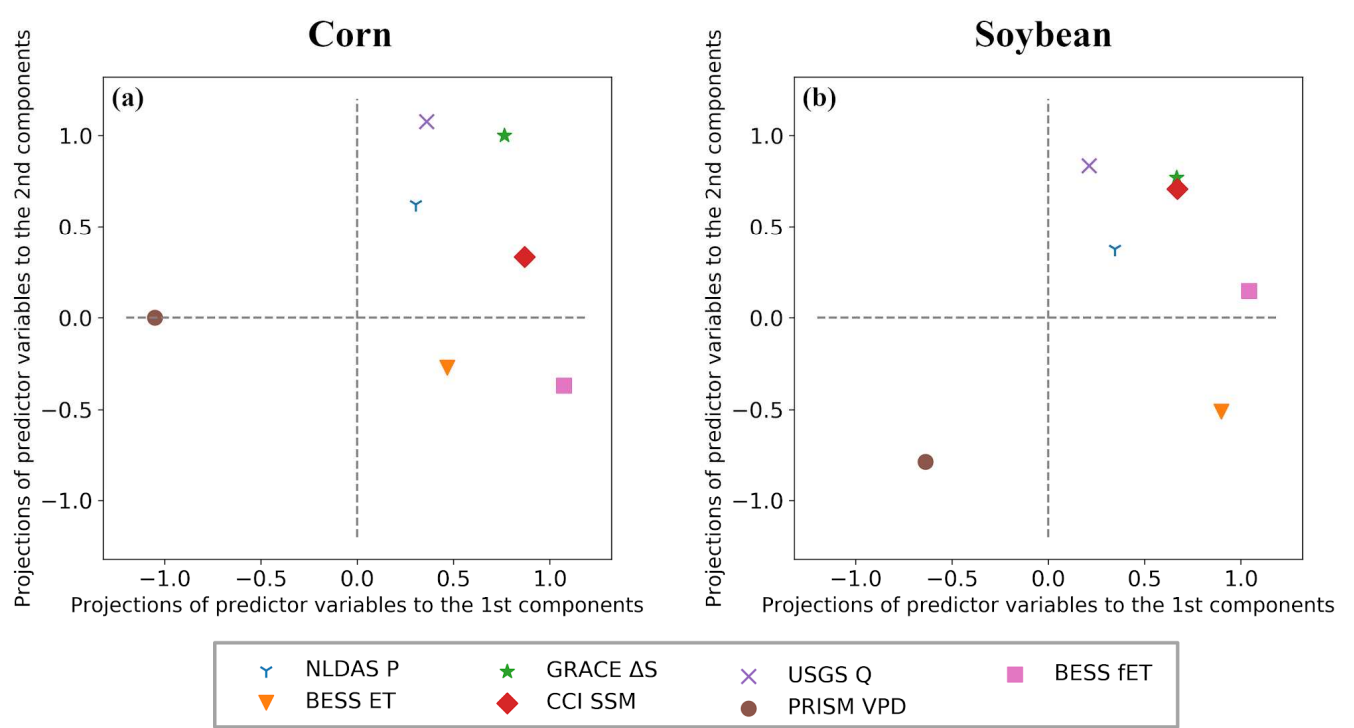

\begin{tabular}{|llllll|}
\hline$y$ & NLDAS P & $\star$ & GRACE $\triangle S$ & $\times$ & USGS Q \\
$\nabla$ & BESS ET & $\bullet$ & $C C I S S M$ & $\bullet$ & PRISM VPD
\end{tabular}

606

607

608

609

610

611

612

613

614

615

616

617

618

619

620

621

622

623

Figure 10. PLSR loadings of different predictor variables for the 1st component (x-axis) and the 2nd component (y-axis) of the PLSR models for (a) corn and (b) soybean.

In the PLSR model, the first two components could explain $70 \%$ and $56 \%$ of the annual yield variabilities for corn and soybean, respectively. For corn, the first and second components explain $51 \%$ and $19 \%$ of yield variability, respectively. For soybean, the first and second components explain $33 \%$ and $23 \%$ of yield variability, respectively. The loading of the first component of the PLSR model (i.e. Figure 9) for both corn and soybean yields can be largely explained by the seasonal correlation between the anomalies in crop yield and hydrological variables (Figure 2). For corn, the first PLSR component mainly contains the hydrological information in July and August; and for soybean, the first PLSR component mainly contains the hydrological information in June and August. The seasonally integrated loading of the different hydrological variables in the first and second PLSR components is presented in Figure 10. For corn, the first component of the PLSR model mainly consisted of VPD, fET and CCI SSM, which predominantly represents water deficit information pertaining to atmospheric demand and near surface soil water storage; while the second component mainly consists of USGS Q, GRACE $\triangle \mathrm{S}$ and NLDAS P, as an indicator of long term groundwater availability. For soybean, the first PLSR component mainly consists of fET, BESS ET and 
VPD, indicating the importance of water demand for soybean growth; while the second component mainly consists of USGS Q, GRACE $\triangle$ S, CCI SSM and VPD, as water supply indicators for crop growth.

\section{Discussion}

In this study, we (1) used multi-source (i.e. observation-based and model-simulated) hydrological cycle components and commonly-used drought indices to assess the best performing plant water stress indicators with the crop yield as a benchmark in the rainfed part of the U.S. Corn Belt; (2) revealed the hydrological causes of huge crop yield losses during the historic 2012 drought by analyzing the progression of water supply and water demand during the drought cycle; (3) and integrated the different hydrological cycle components to establish a new crop-yield-based drought index using the PLSR method. In the following discussion, we synthesize our results to answer the questions raised in the introduction section of the paper.

(1) What is the best indicator to assess the influence of crop water stress among the hydrological cycle components and commonly used drought indices in the rainfed U.S. Corn Belt with crop yield as a benchmark?

Previously, "agricultural drought" has generally been defined based on soil moisture conditions. Our results show that besides soil moisture, VPD and fET also show high correlation with crop yield for both corn and soybean. This finding reveals that both water supply and water demand play vital roles in quantifying plant water stress. Average precipitation is relatively high in the rainfed portions of the U.S. Corn Belt (i.e. 500-1300 $\mathrm{mm} /$ year) which usually ensures adequate soil water to support crop growth during normal years; however, atmospheric water demand still plays a dominant role in determining crop photosynthesis through the leaf stomatal regulation of $\mathrm{CO}_{2}$ exchange (Ort and Long, 2014). Therefore, VPD or fET may be a better indicator to quantify the severity of agricultural 
661

drought in the rainfed U.S. Corn Belt, which is consistent with previous studies (Lobell et al., 2014).

Although different hydrological cycle components show different abilities in quantifying the influence of water stress, most components show a generally similar seasonal pattern in terms of their correlations with crop yield losses, and associated moisture deficits occurring during critical corn and soybean growth stages in the U.S. Corn Belt. The highest correlations between the selected drought metrics and annual crop yield anomalies occurred during the peak growing season (i.e. July for corn and August for soybean). These results indicate that a more accurate definition of "agricultural drought" should emphasize hydrological cycle restrictions occurring during critical crop growth stages.

Although both soil moisture and VPD were able to capture agricultural drought and its evolution in the U.S. Corn Belt, the soil moisture products (both satellite and model-based) had larger uncertainties compared with the VPD data. However, when benchmarked with crop yield, we found that VPD, soil moisture, and fET had generally consistent performance in quantifying drought stress (Figure 11). For example, the crop yield correspondence $(|\boldsymbol{r}|)$ with CCI SSM and VPD increased from April to July for corn and from May to August for soybean, but was lower from July to October for corn and from August to October for soybean as shown in Figure 11b. These findings indicate that VPD may be a better indicator of agricultural drought when considering data availability and uncertainty, and overall performance in quantifying drought stress.
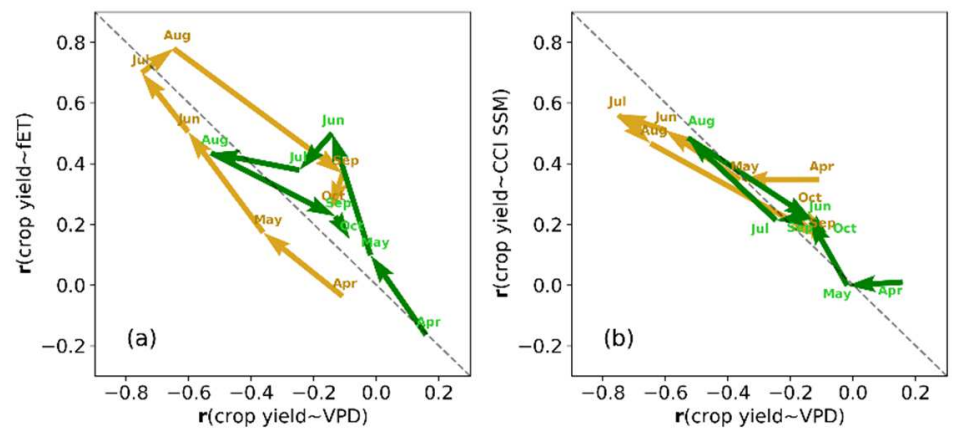

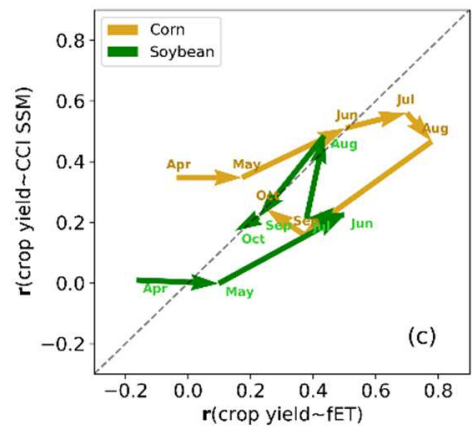


673 Figure 11. The coevolution of the correlation coefficients between crop yield and VPD, 674 between crop yield and fET, and between crop yield and CCI SSM for both corn and soybean.

675 (2) What is the performance of the hydrological cycle components and drought indices in 676 indicating crop yield loss in the extreme drought year of 2012 ?

677 As one of the most severe drought events in U.S. history, the 2012 drought caused large crop 678 yield losses in the U.S. Corn Belt. As shown in Figure 12, the $|r|$ between crop yield and the 679 hydrological cycle components and drought indices in 2012 showed similar seasonal patterns 680 as in other years (i.e. Figure 2), but with higher correlation coefficients. Among the 681 observation-based hydrological cycle components, P showed a higher correlation with crop 682 yield in May and June for corn and in July for soybean. Among the drought indices, VPD 683 showed a higher correlation with crop yield, and provided earlier warning of drought-induced 684 declines in annual corn and soybean production.

By investigating the seasonal cycle and propagation of the hydrological variables in 2012, we 686 find that this drought began with abnormally higher atmospheric water demand (i.e. VPD and 687 PET) and water depletion (due to the high ET) in the spring of 2012, and aggravated by lower water supply (i.e. P) in the early summer. These combined effects significantly lowered soil moisture, leading to abnormally low levels of both surface soil moisture (i.e. CCI SSM) and 690 deeper groundwater (i.e. GRACE $\Delta \mathrm{S}$ ), which exacerbated the drought and contributed to 691 extensive annual crop yield losses. Among the drought indices examined, VPD provided 692 therefore an earlier warning and continued to be an anomaly throughout the growing season 693 compared to other more traditional drought indices (i.e. SPEI and PDSI). Our findings 694 indicate that in the U.S. Corn Belt, the 2012 drought was characterized by excessive 695 atmospheric water demand (i.e. VPD and PET) exacerbated by anomalously low water supply 696 levels (i.e. P and soil moisture). 


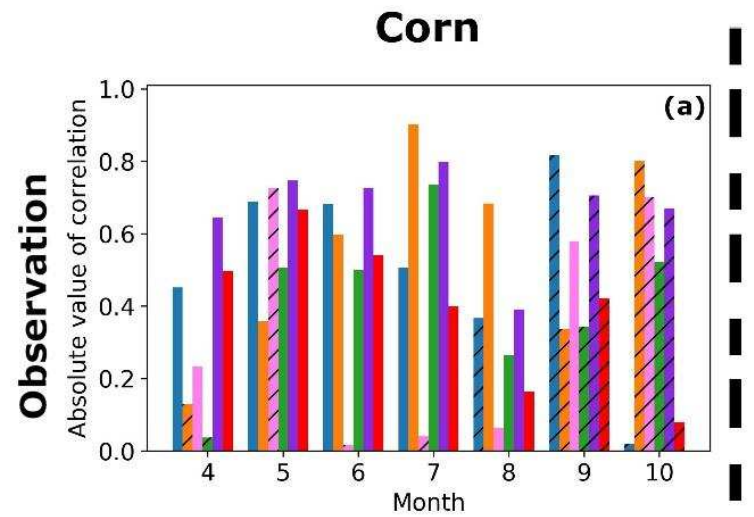

Soybean
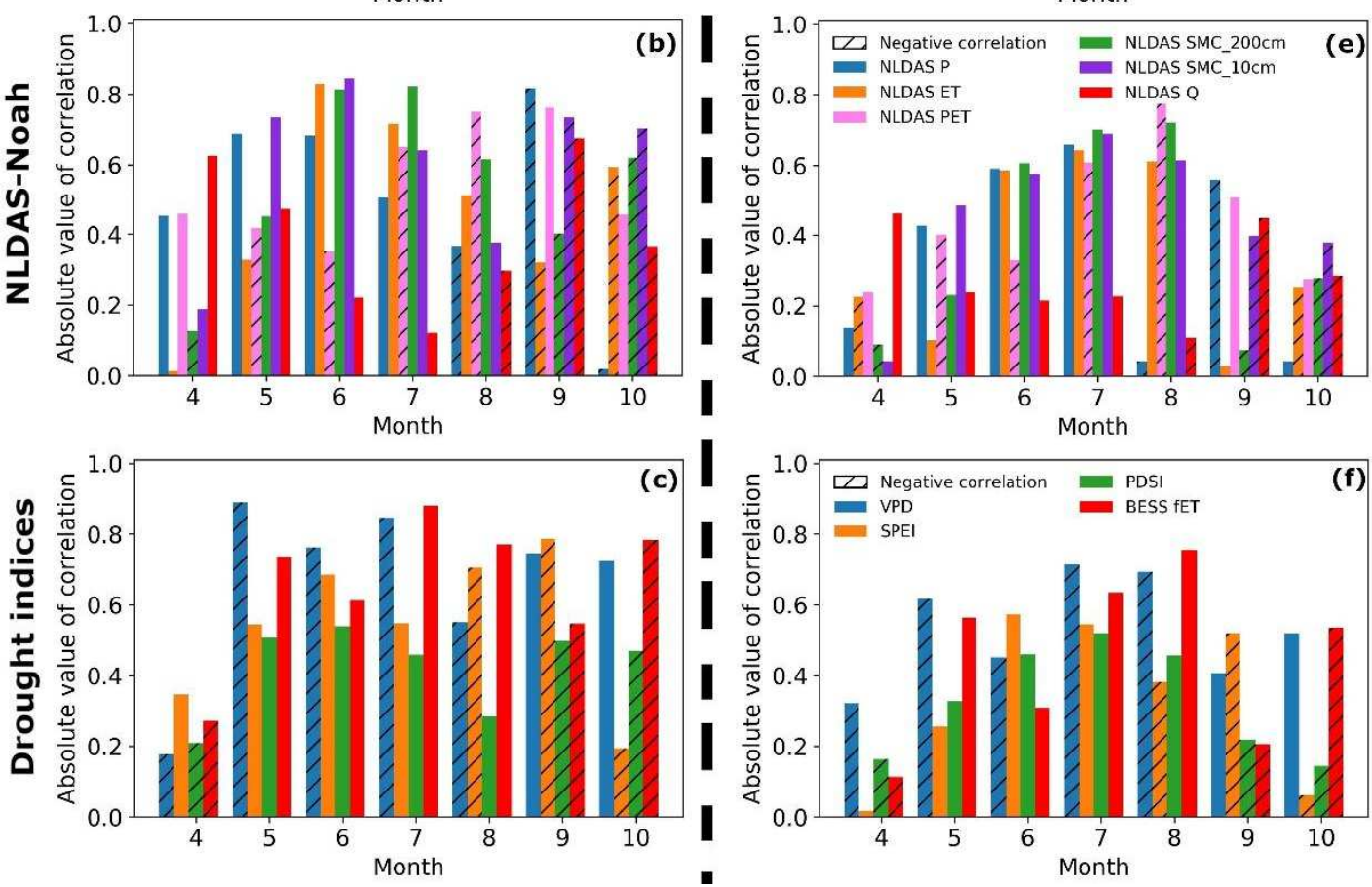

Figure 12. The correlation between hydrological cycle components or drought indices anomalies and yield anomalies for corn and soybean in the 2012 drought year.

(3) How can we optimally integrate the hydrological cycle components and drought indices to assess agricultural drought? What are the contributions of the hydrological cycle components to the new drought index and crop yield predictions?

We further used multiple hydrological cycle components to build a new drought index, defined as the Z-score of seasonal optimal PLSR-based yield prediction, in which the mean and standard deviation were calculated using monthly predicted crop yield from 2003 to 2014. The Z-score is a commonly used metric in drought monitoring (Du et al., 2019; Mu et al., 2013; Zhao et al., 2017). As shown in Figure 8, the performance of the new drought index 
in crop yield prediction increases with more hydrological information ingested in later months, and the $\mathrm{R}^{2}$ reached 0.76 and 0.70 in September for corn and soybean, respectively. The proposed drought index can provide more information about the impact of drought on crop yield compared with other existing indices (i.e. Figure 2). In the new proposed index, crop water supply, water demand, crop growth stages, and their influence on crop yield loss all were considered compared to traditional drought indices (i.e. SPEI, PDSI). For most months, VPD and fET showed larger contributions to the new drought index indicating the vital role of water demand in quantifying agricultural drought in the rainfed U.S. Corn Belt (i.e. Figure 9).

We used annual crop yields for corn and soybean as benchmarks to assess the agricultural drought indices in this study. However, the drought indices may have different impacts on other crop species due to their different physiological characteristics and growth stages. As shown in Figure 13, the newly defined drought index showed different severity of 2012 drought in both magnitude and seasonal evolvement for corn and soybean. For corn, the drought signal was present since the planting month (i.e. May), and became exacerbated during the critical growth stages in June and July. For soybean, the new drought index showed relatively normal conditions in the spring but evolved to be anomalously severe in the following months. The PLSR-based drought index developed in this study contained cumulative hydrological cycle information during the growth season, and provided better forecasts of drought-induced annual crop yield losses than any single hydrological cycle component (i.e. Figure 5). In addition, this new drought index uses crop yield as a benchmark, and may provide more crop-specific agricultural drought assessments and yield forecasts than traditional drought indices. As shown in Figure 14, the PLSR-based crop-specific drought index (Figure 14 (b) and (e)) is more similar to the anomaly of the crop yield for both corn (Figure 14 (a)) and soybean (Figure 14 (d)) compared to VPD in July (Figure 14 (c)) and August (Figure 14 (f)), which shows the highest correlation with the crop yield in July and August for corn and soybean, respectively. These results indicate that the proposed PLSR- 
based drought index has strong potential for agricultural drought monitoring applications.

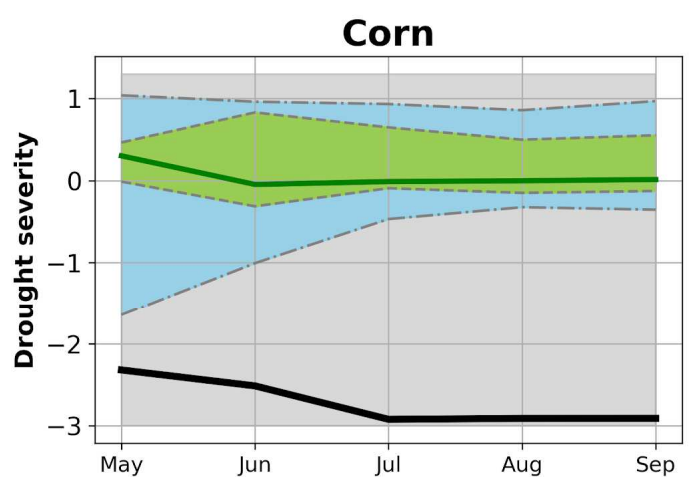

Extreme year 2012 - 50\% percentile

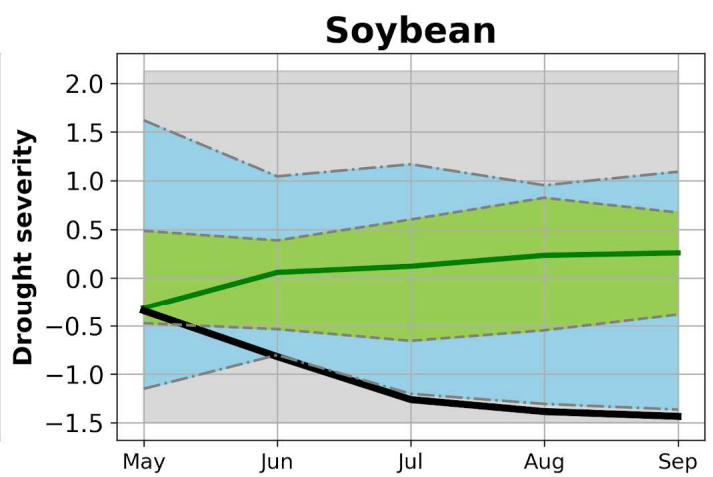

Upper and lower 10\% Upper and lower 25\%

Figure 13. Seasonal evolution of PLSR-based drought index in 2012 with percentiles calculated using all of the data from 2003 to 2014. The black line indicates the seasonal cycle of the normalized drought index in 2012. The dark green curve indicates the 50\% percentiles, the blue shade indicates the upper and lower 10\% ranges, and the light green shade indicates the upper and lower quartiles of monthly normalized drought index, respectively. 
(a) Z-score of NASS detrended corn yield
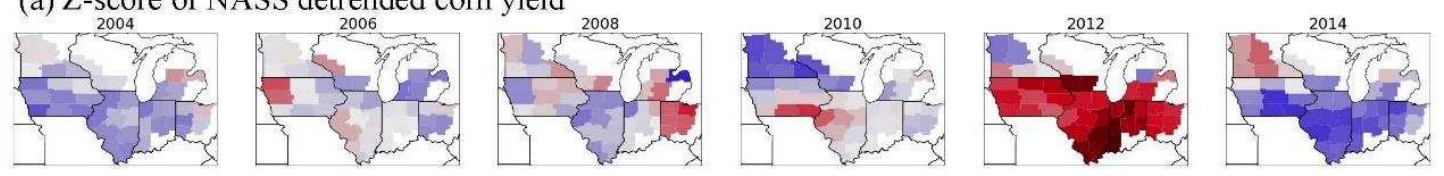

(b) PLSR-based drought indices for corn in September
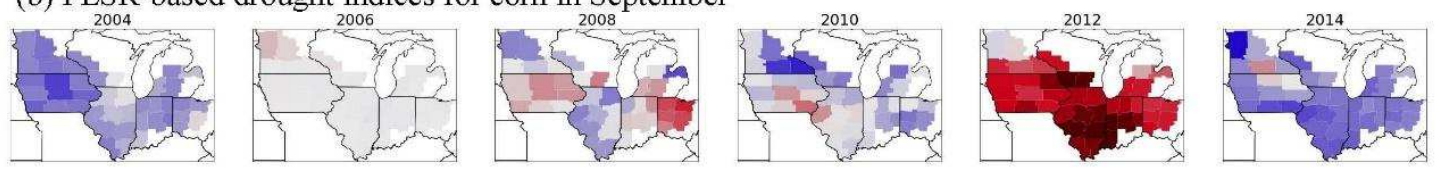

(c) Z-score of negative VPD in July
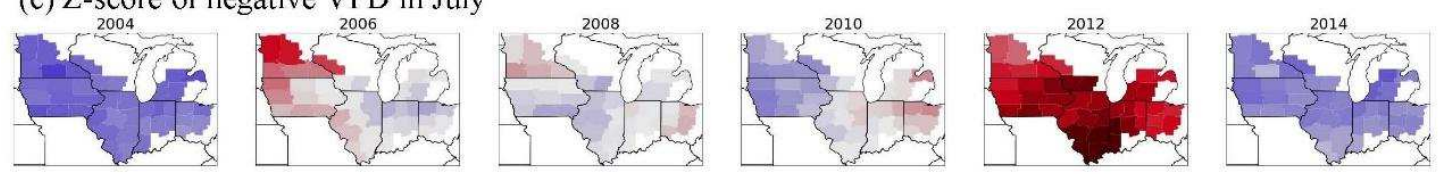

(d) Z-score of NASS detrended soybean yield
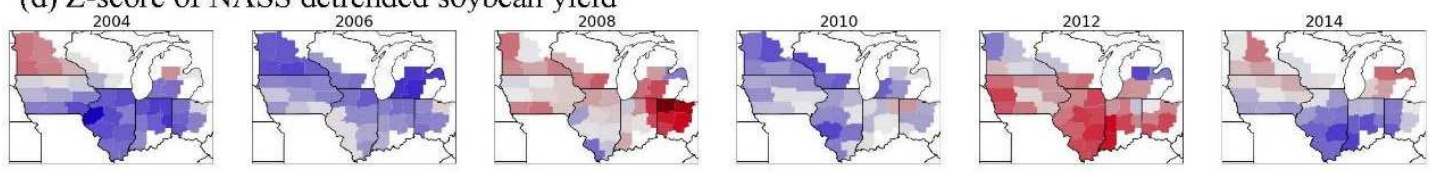

(e) PLSR-based drought indices for soybean in September
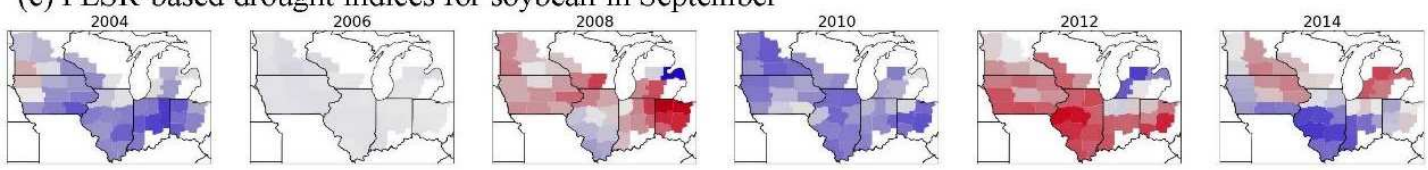

(f) Z-score of negative VPD in August
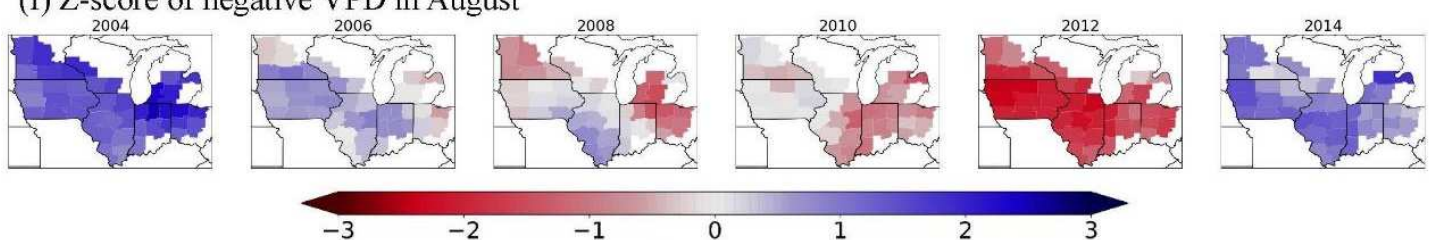

Z-score

Figure 14. Comparison among the normalized detrended corn and soybean yield (a and d); PLSR-

based agricultural drought index in September for corn and soybean ( $b$ and e); and the normalized

VPD in July and August (c and f).

\section{Conclusion}

In summary, we quantified the response of corn and soybean crop yields to hydrological variability over the rainfed part of the U.S. Corn Belt at the agricultural district scale from 2003 to 2014. Our analysis investigated the anomaly relationships between corn/soybean

754 yield and monthly hydrological cycle components, and selected commonly used drought indices, as well as the spatio-temporal dynamics of such relationships. We analyzed the impacts on crop yield and the underlying hydrological cycle drivers of the 2012 drought in 
relation to the recent period (2003 to 2014). We also integrated the hydrological cycle components and drought index metrics within an empirical modeling framework (i.e. PLSR) as a means for improving annual crop yield forecasts and drought related impacts assessment.

We concluded our study as following: (1) Overall, the relationship between crop yield and the hydrological cycle components and drought indices, and its spatio-temporal dynamics is consistent with the evolution of crop growth stages in the Corn Belt. The CCI SSM and VPD/fET showed the strongest anomaly correlation with crop yield among all other observation-based hydrological cycle components and drought indices examined in this study. In the rainfed Corn Belt, although soil moisture plays a vital role in quantifying agricultural drought effects, VPD may be the dominant water stress indicator of crop growth and end-ofseason yield. (2) By analyzing the evolution of the hydrological cycle components and drought indices in 2012, we found that this severe drought in the rainfed U.S. Corn Belt started with higher water demand (i.e. PET, VPD), water consumption (i.e. ET), and lower water supply (i.e. P), followed by excessive soil water depletion (i.e. CCI CCM, GRACE $\Delta \mathrm{S}$ ), which ultimately led to large crop yield losses in 2012. Among all of the hydrological cycle components and drought indices examined, VPD gives the earliest warning of potential crop yield losses and its anomaly continued throughout the growing season. (3) The validated $R^{2}$ of the PLSR-based crop yield model reached favorable levels of 0.76 and 0.70 for corn and soybean, respectively. The relatively strong PLSR performance benefitted from complementary value-added information provided from multiple hydrological cycle input variables. The first PLSR component explained 51\% and 33\% of crop yield variability for corn and soybean, respectively. For corn, the first model component primarily included information about the atmospheric water deficit (i.e. VPD, fET) and near surface soil water storage (i.e. CCI SSM); For soybean, the first component mainly contains information about the atmospheric water deficit (i.e. VPD, fET) and water demand (i.e. BESS ET). These results provide enhanced information on water supply and demand constraints affecting agricultural drought, and effective early warning of drought related impacts on annual yields for the two 
dominant crop types in the U.S. Corn belt.

\section{Acknowledgments}

Guan and Peng acknowledge USDA grants (including Hatch) and NREC grant. Zhou and Shi acknowledge the support from the UCAS Joint PhD Training Program.

\section{References}

Alley, W.M., 1984. The Palmer Drought Severity Index: Limitations and Assumptions. J. Clim. Appl. Meteorol. 23, 1100-1109. https://doi.org/10.1175/15200450(1984)023<1100:TPDSIL>2.0.CO;2

Anderson, D.B., 1936. Relative Humidity or Vapor Pressure Deficit. Ecology 17, 277-282. https://doi.org/10.2307/1931468

Anderson, M.C., Hain, C., Otkin, J., Zhan, X., Mo, K., Svoboda, M., Wardlow, B., Pimstein, A., 2013. An Intercomparison of Drought Indicators Based on Thermal Remote Sensing and NLDAS-2 Simulations with U.S. Drought Monitor Classifications. J. Hydrometeorol. 14, 1035-1056. https://doi.org/10.1175/JHM-D-12-0140.1

Anderson, M.C., Hain, C.R., Jurecka, F., Trnka, M., Hlavinka, P., Dulaney, W., Otkin, J.A., Johnson, D., Gao, F., 2016a. Relationships between the evaporative stress index and winter wheat and spring barley yield anomalies in the Czech Republic. Clim. Res. 70, 215-230. https://doi.org/10.3354/cr01411

Anderson, M.C., Norman, J.M., Mecikalski, J.R., Otkin, J.A., Kustas, W.P., 2007a. A climatological study of evapotranspiration and moisture stress across the continental United States based on thermal remote sensing: 1. Model formulation. J. Geophys. Res. Atmos. 112, 1-17. https://doi.org/10.1029/2006JD007506

Anderson, M.C., Norman, J.M., Mecikalski, J.R., Otkin, J.A., Kustas, W.P., 2007b. A climatological study of evapotranspiration and moisture stress across the continental United States based on thermal remote sensing: 2. Surface moisture climatology. J. Geophys. Res. 112, D11112. https://doi.org/10.1029/2006JD007507 
Anderson, M.C., Zolin, C.A., Sentelhas, P.C., Hain, C.R., Semmens, K., Tugrul Yilmaz, M., Gao, F., Otkin, J.A., Tetrault, R., 2016b. The Evaporative Stress Index as an indicator of agricultural drought in Brazil: An assessment based on crop yield impacts. Remote Sens. Environ. 174, 82-99. https://doi.org/10.1016/j.rse.2015.11.034

Andreadis, K.M., Clark, E.A., Wood, A.W., Hamlet, A.F., Lettenmaier, D.P., 2005. Twentieth-Century Drought in the Conterminous United States. J. Hydrometeorol. 6, 985-1001. https://doi.org/10.1175/JHM450.1

Anyamba, A., Small, J.L., Britch, S.C., Tucker, C.J., Pak, E.W., Reynolds, C.A., Crutchfield, J., Linthicum, K.J., 2014. Recent Weather Extremes and Impacts on Agricultural Production and Vector-Borne Disease Outbreak Patterns. PLoS One 9, e92538. https://doi.org/10.1371/journal.pone.0092538

Beguería, S., Vicente-Serrano, S.M., Reig, F., Latorre, B., 2014. Standardized precipitation evapotranspiration index (SPEI) revisited: Parameter fitting, evapotranspiration models, tools, datasets and drought monitoring. Int. J. Climatol. 34, 3001-3023. https://doi.org/10.1002/joc.3887

Biradar, C.M., Thenkabail, P.S., Noojipady, P., Li, Y., Dheeravath, V., Turral, H., Velpuri, M., Gumma, M.K., Gangalakunta, O.R.P., Cai, X.L., Xiao, X., Schull, M.A., Alankara, R.D., Gunasinghe, S., Mohideen, S., 2009. A global map of rainfed cropland areas (GMRCA) at the end of last millennium using remote sensing. Int. J. Appl. Earth Obs. Geoinf. 11, 114-129. https://doi.org/10.1016/j.jag.2008.11.002

Bolten, J., Crow, W., Zhan, X., Jackson, T., Reynolds, C., Doom, B., 2006. The application of AMSR-E soil moisture for improved global agricultural assessment and forecasting. Int. Geosci. Remote Sens. Symp. 2032-2035. https://doi.org/10.1109/IGARSS.2006.526

Bolten, J.D., Crow, W.T., Jackson, T.J., Zhan, X., Reynolds, C.A., 2010. Evaluating the Utility of Remotely Sensed Soil Moisture Retrievals for Operational Agricultural Drought Monitoring. IEEE J. Sel. Top. Appl. Earth Obs. Remote Sens. 3, 57-66. https://doi.org/10.1109/JSTARS.2009.2037163

Bonan, G.B., Williams, M., Fisher, R.A., Oleson, K.W., 2014. Modeling stomatal 
conductance in the earth system: linking leaf water-use efficiency and water transport along the soil-plant-atmosphere continuum. Geosci. Model Dev. 7, 2193-2222. https://doi.org/10.5194/gmd-7-2193-2014

Boyer, J.S., 1970. Differing Sensitivity of Photosynthesis to Low Leaf Water Potentials in Corn and Soybean. Plant Physiol. 46, 236-239. https://doi.org/10.1104/pp.46.2.236

Brown, M.E., Funk, C.C., 2008. Food Security Under Climate Change. Science (80). 319, 580-581. https://doi.org/10.1126/science.1154102

Çakir, R., 2004. Effect of water stress at different development stages on vegetative and reproductive growth of corn. F. Crop. Res. 89, 1-16. https://doi.org/10.1016/j.fcr.2004.01.005

Cook, E.R., Solomina, O., Matskovsky, V., Cook, B.I., Agafonov, L., Berdnikova, A., Dolgova, E., Karpukhin, A., Knysh, N., Kulakova, M., Kuznetsova, V., Kyncl, T., Kyncl, J., Maximova, O., Panyushkina, I., Seim, A., Tishin, D., Ważny, T., Yermokhin, M., 2020. The European Russia Drought Atlas (1400-2016 CE). Clim. Dyn. 54, 23172335. https://doi.org/10.1007/s00382-019-05115-2

Crow, W., 2014. Assimilation of AMSR-E Soil Moisture Retrievals into the USDA Global Crop Production Decision Support System.

Dai, A., 2019. The Climate Data Guide: Palmer Drought Severity Index (PDSI). https://climatedataguide.ucar.edu/climate-data/palmer-drought-severity-index-pdsi

Dai, A., 2011. Characteristics and trends in various forms of the Palmer Drought Severity Index during 1900-2008. J. Geophys. Res. 116, D12115. https://doi.org/10.1029/2010JD015541

Dai, A., Trenberth, K.E., Qian, T., 2004. A Global Dataset of Palmer Drought Severity Index for 1870-2002: Relationship with Soil Moisture and Effects of Surface Warming. J. Hydrometeorol. 5, 1117-1130. https://doi.org/10.1175/JHM-386.1

Daly, C., Halbleib, M., Smith, J.I., Gibson, W.P., Doggett, M.K., Taylor, G.H., Curtis, J., Pasteris, P.P., 2008. Physiographically sensitive mapping of climatological temperature and precipitation across the conterminous United States. Int. J. Climatol. 28, 2031-2064. 
Dorigo, W., Wagner, W., Albergel, C., Albrecht, F., Balsamo, G., Brocca, L., Chung, D., Ertl, M., Forkel, M., Gruber, A., Haas, E., Hamer, P.D., Hirschi, M., Ikonen, J., de Jeu, R., Kidd, R., Lahoz, W., Liu, Y.Y., Miralles, D., Mistelbauer, T., Nicolai-Shaw, N., Parinussa, R., Pratola, C., Reimer, C., van der Schalie, R., Seneviratne, S.I., Smolander, T., Lecomte, P., 2017. ESA CCI Soil Moisture for improved Earth system

Du, J., Kimball, J.S., Velicogna, I., Zhao, M., Jones, L.A., Watts, J.D., Kim, Y., A, G., 2019. Multicomponent Satellite Assessment of Drought Severity in the Contiguous United States From 2002 to 2017 Using AMSR-E and AMSR2. Water Resour. Res. 55, 5394-

Ge, Y., Cai, X., Zhu, T., Ringler, C., 2016. Drought frequency change: An assessment in 5412. https://doi.org/10.1029/2018WR024633 northern India plains. Agric. Water Manag. 176, 111-121. https://doi.org/10.1016/j.agwat.2016.05.015

Geladi, P., Kowalski, B.R., 1986. Partial least-squares regression: a tutorial. Anal. Chim. Acta 185, 1-17. https://doi.org/10.1016/0003-2670(86)80028-9

Grassini, P., Specht, J.E., Tollenaar, M., Ciampitti, I., Cassman, K.G., 2015. High-yield maize-soybean cropping systems in the US Corn Belt, in: Crop Physiology. Elsevier, pp. 17-41. https://doi.org/10.1016/B978-0-12-417104-6.00002-9

Gruber, A., Dorigo, W.A., Crow, W., Wagner, W., 2017. Triple Collocation-Based Merging of Satellite Soil Moisture Retrievals. IEEE Trans. Geosci. Remote Sens. 55, 6780-6792. https://doi.org/10.1109/TGRS.2017.2734070

Gruber, A., Scanlon, T., van der Schalie, R., Wagner, W., Dorigo, W., 2019. Evolution of the ESA CCI Soil Moisture climate data records and their underlying merging methodology. Earth Syst. Sci. Data 11, 717-739. https://doi.org/10.5194/essd-11-717-2019

Guan, K., Good, S.P., Caylor, K.K., Sato, H., Wood, E.F., Li, H., 2014. Continental-scale impacts of intra-seasonal rainfall variability on simulated ecosystem responses in Africa. 
Guan, K., Sultan, B., Biasutti, M., Baron, C., Lobell, D.B., 2015. What aspects of future rainfall changes matter for crop yields in West Africa? Geophys. Res. Lett. 42, 80018010. https://doi.org/10.1002/2015GL063877

Guan, K., Wu, J., Kimball, J.S., Anderson, M.C., Frolking, S., Li, B., Hain, C.R., Lobell, 902 microwave satellite data for estimating large-scale crop yields. Remote Sens. Environ. 199, 333-349. https://doi.org/10.1016/j.rse.2017.06.043

Han, E., Crow, W.T., Holmes, T., Bolten, J., 2014. Benchmarking a Soil Moisture Data Assimilation System for Agricultural Drought Monitoring. J. Hydrometeorol. 15, 1117 1134. https://doi.org/10.1175/JHM-D-13-0125.1

Hollmann, R., Merchant, C.J., Saunders, R., Downy, C., Buchwitz, M., Cazenave, A., Chuvieco, E., Defourny, P., de Leeuw, G., Forsberg, R., Holzer-Popp, T., Paul, F., Sandven, S., Sathyendranath, S., van Roozendael, M., Wagner, W., 2013. The ESA Climate Change Initiative: Satellite Data Records for Essential Climate Variables. Bull. Am. Meteorol. Soc. 94, 1541-1552. https://doi.org/10.1175/BAMS-D-11-00254.1

Huck, M.G., Ishihara, K., Peterson, C.M., Ushijima, T., 1983. Soybean Adaptation to Water Stress at Selected Stages of Growth. Plant Physiol. 73, 422-427. https://doi.org/10.1104/pp.73.2.422

Hunt, E.D., Svoboda, M., Wardlow, B., Hubbard, K., Hayes, M., Arkebauer, T., 2014. Monitoring the effects of rapid onset of drought on non-irrigated maize with agronomic data and climate-based drought indices. Agric. For. Meteorol. 191, 1-11. https://doi.org/10.1016/j.agrformet.2014.02.001

Huntington, T.G., 2006. Evidence for intensification of the global water cycle: Review and synthesis. J. Hydrol. 319, 83-95. https://doi.org/10.1016/j.jhydrol.2005.07.003

Iizumi, T., Luo, J.-J., Challinor, A.J., Sakurai, G., Yokozawa, M., Sakuma, H., Brown, M.E., Yamagata, T., 2014. Impacts of El Niño Southern Oscillation on the global yields of major crops. Nat. Commun. 5, 3712. https://doi.org/10.1038/ncomms4712 
Jian, X., Wolock, D., Lins, H., 2008. WaterWatch-Maps, Graphs, and Tables of Current, Recent, and Past Streamflow Conditions.

Jiang, C., Ryu, Y., 2016. Multi-scale evaluation of global gross primary productivity and evapotranspiration products derived from Breathing Earth System Simulator (BESS). Remote Sens. Environ. 186, 528-547. https://doi.org/10.1016/j.rse.2016.08.030

Jiang, C., Guan, K., Pan, M., Ryu, Y., Peng, B., Wang, S., 2020. BESS-STAIR: a framework to estimate daily, $30 \mathrm{~m}$, and all-weather crop evapotranspiration using multi-source satellite data for the US Corn Belt. Hydrol. Earth Syst. Sci. 24, 1251-1273. https://doi.org/10.5194/hess-24-1251-2020

Kennedy, D., Swenson, S., Oleson, K.W., Lawrence, D.M., Fisher, R., Lola da Costa, A.C., Gentine, P., 2019. Implementing Plant Hydraulics in the Community Land Model, Version 5. J. Adv. Model. Earth Syst. 11, 485-513. https://doi.org/10.1029/2018MS001500

Landerer, F.W., Swenson, S.C., 2012. Accuracy of scaled GRACE terrestrial water storage estimates. Water Resour. Res. 48, 1-11. https://doi.org/10.1029/2011WR011453

Li, Y., Guan, K., Yu, A., Peng, B., Zhao, L., Li, B., Peng, J., 2019. Toward building a transparent statistical model for improving crop yield prediction: Modeling rainfed corn in the U.S. F. Crop. Res. 234, 55-65. https://doi.org/10.1016/j.fcr.2019.02.005

Lobell, D.B., Roberts, M.J., Schlenker, W., Braun, N., Little, B.B., Rejesus, R.M., Hammer, G.L., 2014. Greater Sensitivity to Drought Accompanies Maize Yield Increase in the U.S. Midwest. Science (80). 344, 516-519. https://doi.org/10.1126/science.1251423

Lu, J., Carbone, G.J., Gao, P., 2017. Detrending crop yield data for spatial visualization of drought impacts in the United States, 1895-2014. Agric. For. Meteorol. 237-238, 196208. https://doi.org/10.1016/j.agrformet.2017.02.001

Luo, L., Apps, D., Arcand, S., Xu, H., Pan, M., Hoerling, M., 2017. Contribution of temperature and precipitation anomalies to the California drought during 2012-2015. Geophys. Res. Lett. 44, 3184-3192. https://doi.org/10.1002/2016GL072027

Mallya, G., Zhao, L., Song, X.C., Niyogi, D., Govindaraju, R.S., 2013. 2012 Midwest 
Drought in the United States. J. Hydrol. Eng. 18, 737-745. https://doi.org/10.1061/(ASCE)HE.1943-5584.0000786

Martínez-Vilalta, J., Poyatos, R., Aguadé, D., Retana, J., Mencuccini, M., 2014. A new look at water transport regulation in plants. New Phytol. 204, 105-115. https://doi.org/10.1111/nph.12912

Masud, M.B., Khaliq, M.N., Wheater, H.S., 2015. Analysis of meteorological droughts for the Saskatchewan River Basin using univariate and bivariate approaches. J. Hydrol. 522, 452-466. https://doi.org/10.1016/j.jhydrol.2014.12.058

McKee, T.B., Doesken, N.J., Kleist, J., 1993. The relationship of drought frequency and duration to time scales. Proc. 8th Conf. Appl. Climatol. 17-22 January 1993. Anaheim, CA, Am. Meteorol. Soc. 179-184.

Meyer, S.J., Hubbard, K.G., Wilhite, D.A., 1993. A Crop-Specific Drought Index for Corn: I. Model Development and Validation. Agron. J. 85, 388. https://doi.org/10.2134/agronj1993.00021962008500020040x

Milly, P.C.D., Dunne, K.A., 2016. Potential evapotranspiration and continental drying. Nat. Clim. Chang. 6, 946-949. https://doi.org/10.1038/nclimate3046

Mishra, A.K., Singh, V.P., 2010. A review of drought concepts. J. Hydrol. 391, 202-216. https://doi.org/10.1016/j.jhydrol.2010.07.012

Mishra, V., Cherkauer, K.A., 2010. Retrospective droughts in the crop growing season: Implications to corn and soybean yield in the Midwestern United States. Agric. For. Meteorol. 150, 1030-1045. https://doi.org/10.1016/j.agrformet.2010.04.002

Mitchell, K.E., 2004. The multi-institution North American Land Data Assimilation System (NLDAS): Utilizing multiple GCIP products and partners in a continental distributed hydrological modeling system. J. Geophys. Res. 109, D07S90. https://doi.org/10.1029/2003JD003823

Mladenova, I.E., Bolten, J.D., Crow, W.T., Anderson, M.C., Hain, C.R., Johnson, D.M., Mueller, R., 2017. Intercomparison of Soil Moisture, Evaporative Stress, and Vegetation Indices for Estimating Corn and Soybean Yields Over the U.S. IEEE J. Sel. Top. Appl. 

Earth Obs. Remote Sens. 10, 1328-1343. https://doi.org/10.1109/JSTARS.2016.2639338

Mu, Q., Zhao, M., Kimball, J.S., McDowell, N.G., Running, S.W., 2013. A Remotely Sensed Global Terrestrial Drought Severity Index. Bull. Am. Meteorol. Soc. 94, 83-98. https://doi.org/10.1175/BAMS-D-11-00213.1

Muller, B., Pantin, F., Génard, M., Turc, O., Freixes, S., Piques, M., Gibon, Y., 2011. Water deficits uncouple growth from photosynthesis, increase $\mathrm{C}$ content, and modify the relationships between $\mathrm{C}$ and growth in sink organs. J. Exp. Bot. 62, 1715-1729. https://doi.org/10.1093/jxb/erq438

Njoku, E.G., Entekhabi, D., 1996. Passive microwave remote sensing of soil moisture. J. Hydrol. 184, 101-129. https://doi.org/10.1016/0022-1694(95)02970-2

Njoku, E.G., Jackson, T.J., Lakshmi, V., Chan, T.K., Nghiem, S.V., 2003. Soil moisture retrieval from AMSR-E. IEEE Trans. Geosci. Remote Sens. 41, 215-229. https://doi.org/10.1109/TGRS.2002.808243

Nocco, M.A., Smail, R.A., Kucharik, C.J., 2019. Observation of irrigation-induced climate change in the Midwest United States. Glob. Chang. Biol. 25, 3472-3484. https://doi.org/10.1111/gcb.14725

Novick, K.A., Ficklin, D.L., Stoy, P.C., Williams, C.A., Bohrer, G., Oishi, A.C., Papuga, S.A., Blanken, P.D., Noormets, A., Sulman, B.N., Scott, R.L., Wang, L., Phillips, R.P., 2016. The increasing importance of atmospheric demand for ecosystem water and carbon fluxes. Nat. Clim. Chang. 6, 1023-1027. https://doi.org/10.1038/nclimate3114

Oki, T., Kanae, S., 2006. Global Hydrological Cycles and World Water Resources. Science (80-. ). 313, 1068-1072. https://doi.org/10.1126/science.1128845

Orellana, F., Verma, P., Loheide, S.P., Daly, E., 2012. Monitoring and modeling watervegetation interactions in groundwater-dependent ecosystems. Rev. Geophys. 50. https://doi.org/10.1029/2011RG000383

Ort, D.R., Long, S.P., 2014. Limits on Yields in the Corn Belt. Science. 344, 484-485. https://doi.org/10.1126/science.1253884

Otkin, J.A., Anderson, M.C., Hain, C., Mladenova, I.E., Basara, J.B., Svoboda, M., 2013. 

Examining Rapid Onset Drought Development Using the Thermal Infrared-Based Evaporative Stress Index. J. Hydrometeorol. 14, 1057-1074. https://doi.org/10.1175/JHM-D-12-0144.1

Otkin, J.A., Anderson, M.C., Hain, C., Svoboda, M., 2014. Examining the Relationship between Drought Development and Rapid Changes in the Evaporative Stress Index. J. Hydrometeorol. 15, 938-956. https://doi.org/10.1175/JHM-D-13-0110.1

Ouyang, Y., 2002. Phytoremediation: modeling plant uptake and contaminant transport in the soil-plant-atmosphere continuum. J. Hydrol. 266, 66-82. https://doi.org/10.1016/S0022-1694(02)00116-6

Palmer, W.C., 1965. Meteorological drought. US Department of Commerce. Research Paper 45.

Peng, B., Guan, K., Chen, M., Lawrence, D.M., Pokhrel, Y., Suyker, A., Arkebauer, T., Lu, Y., 2018a. Improving maize growth processes in the community land model: Implementation and evaluation. Agric. For. Meteorol. 250-251, 64-89. https://doi.org/10.1016/j.agrformet.2017.11.012

Peng, B., Guan, K., Pan, M., Li, Y., 2018b. Benefits of seasonal climate prediction and satellite data for forecasting US maize yield. Geophys. Res. Lett. https://doi.org/10.1029/2018GL079291

Peng, B., Guan, K., Tang, J., Ainsworth, E.A., Asseng, S., Bernacchi, C.J., Cooper, M., Delucia, E.H., Elliott, J.W., Ewert, F., Grant, R.F., Gustafson, D.I., Hammer, G.L., Jin, Z., Jones, J.W., Kimm, H., Lawrence, D.M., Li, Y., Lombardozzi, D.L., MarshallColon, A., Messina, C.D., Ort, D.R., Schnable, J.C., Vallejos, C.E., Wu, A., Yin, X., Zhou, W., 2020a. Towards a multiscale crop modelling framework for climate change adaptation assessment. Nat. Plants 6, 338-348. https://doi.org/10.1038/s41477-0200625-3

Peng, B., Guan, K., Zhou, W., Jiang, C., Frankenberg, C., Sun, Y., He, L., Köhler, P., 2020b. Assessing the benefit of satellite-based Solar-Induced Chlorophyll Fluorescence in crop yield prediction. Int. J. Appl. Earth Obs. Geoinf. 90, 102126. 

https://doi.org/10.1016/j.jag.2020.102126

Peng, B., Zhao, T., Shi, J., Lu, H., Mialon, A., Kerr, Y.H., Liang, X., Guan, K., 2017. Reappraisal of the roughness effect parameterization schemes for L-band radiometry over bare soil. Remote Sens. Environ. 199, 63-77. https://doi.org/10.1016/j.rse.2017.07.006

Rippey, B.R., 2015. The U.S. drought of 2012. Weather Clim. Extrem. 10, 57-64. https://doi.org/10.1016/j.wace.2015.10.004

Rosenzweig, C., Iglesias, A., Yang, X.B., Epstein, P.R., Chivian, E., 2001. Climate change and extreme weather events: implications for food production, plant diseases, and pests. Glob. Chang. Hum. Heal. 2, 90-104. https://doi.org/10.1023/A:1015086831467

Ryu, Y., Baldocchi, D.D., Kobayashi, H., van Ingen, C., Li, J., Black, T.A., Beringer, J., van Gorsel, E., Knohl, A., Law, B.E., Roupsard, O., 2011. Integration of MODIS land and atmosphere products with a coupled-process model to estimate gross primary productivity and evapotranspiration from $1 \mathrm{~km}$ to global scales. Global Biogeochem. Cycles 25. https://doi.org/10.1029/2011GB004053

Sakumura, C., Bettadpur, S., Bruinsma, S., 2014. Ensemble prediction and intercomparison analysis of GRACE time-variable gravity field models. Geophys. Res. Lett. 41, 13891397. https://doi.org/10.1002/2013GL058632

Seager, R., Hooks, A., Williams, A.P., Cook, B., Nakamura, J., Henderson, N., 2015. Climatology, variability, and trends in the U.S. Vapor pressure deficit, an important firerelated meteorological quantity. J. Appl. Meteorol. Climatol. 54, 1121-1141. https://doi.org/10.1175/JAMC-D-14-0321.1

Sheffield, J., Wood, E.F., Roderick, M.L., 2012. Little change in global drought over the past 60 years. Nature 491, 435-438. https://doi.org/10.1038/nature11575

Sperry, J.S., Hacke, U.G., Oren, R., Comstock, J.P., 2002. Water deficits and hydraulic limits to leaf water supply. Plant, Cell Environ. 25, 251-263. https://doi.org/10.1046/j.00168025.2001.00799.x

Sulman, B.N., Roman, D.T., Yi, K., Wang, L., Phillips, R.P., Novick, K.A., 2016. High 

atmospheric demand for water can limit forest carbon uptake and transpiration as severely as dry soil. Geophys. Res. Lett. 43, 9686-9695. https://doi.org/10.1002/2016GL069416

Svoboda, M., LeComte, D., Hayes, M., Heim, R., Gleason, K., Angel, J., Rippey, B., Tinker, R., Palecki, M., Stooksbury, D., Miskus, D., Stephens, S., 2002. The Drought Monitor. Bull. Am. Meteorol. Soc. 83, 1181-1190. https://doi.org/10.1175/1520-0477-83.8.1181

Tian, L., Yuan, S., Quiring, S.M., 2018. Evaluation of six indices for monitoring agricultural drought in the south-central United States. Agric. For. Meteorol. 249, 107-119. https://doi.org/10.1016/j.agrformet.2017.11.024

Turner, N.C., Begg, J.E., 1981. Plant-water relations and adaptation to stress. Plant Soil 58, 97-131. https://doi.org/10.1007/BF02180051

Tyree, M.T., Ewers, F.W., 1991. The hydraulic architecture of trees and other woody plants. New Phytol. 119, 345-360. https://doi.org/10.1111/j.1469-8137.1991.tb00035.x

Vicente-Serrano, S.M., 2015. The Climate Data Guide: Standardized Precipitation Evapotranspiration Index (SPEI). https://climatedataguide.ucar.edu/climatedata/standardized-precipitation-evapotranspiration-index-spei

Vicente-Serrano, S.M., Beguería, S., López-Moreno, J.I., 2010. A Multiscalar Drought Index Sensitive to Global Warming: The Standardized Precipitation Evapotranspiration Index. J. Clim. 23, 1696-1718. https://doi.org/10.1175/2009JCLI2909.1

Wayne, C.P., 1965. Meteorological drought. US Weather Bur. Res. Pap.

Wells, N., Goddard, S., Hayes, M.J., 2004. A Self-Calibrating Palmer Drought Severity Index. J. Clim. 17, 2335-2351. https://doi.org/10.1175/15200442(2004)017<2335:ASPDSI >2.0.CO;2

Wigneron, J.-P., Jackson, T.J., O’Neill, P., De Lannoy, G., de Rosnay, P., Walker, J.P., Ferrazzoli, P., Mironov, V., Bircher, S., Grant, J.P., Kurum, M., Schwank, M., MunozSabater, J., Das, N., Royer, A., Al-Yaari, A., Al Bitar, A., Fernandez-Moran, R., Lawrence, H., Mialon, A., Parrens, M., Richaume, P., Delwart, S., Kerr, Y., 2017. Modelling the passive microwave signature from land surfaces: A review of recent 
results and application to the L-band SMOS \&amp; SMAP soil moisture retrieval $\begin{array}{lllll}\text { algorithms. } & \text { Remote } & \text { Sens. }\end{array}$ https://doi.org/10.1016/j.rse.2017.01.024

Williams, M., Rastetter, E.B., Fernandes, D.N., Goulden, M.L., Wofsy, S.C., Shaver, G.R., Melillo, J.M., Munger, J.W., Fan, S.-M., Nadelhoffer, K.J., 1996. Modelling the soilplant-atmosphere continuum in a Quercus-Acer stand at Harvard Forest: the regulation of stomatal conductance by light, nitrogen and soil/plant hydraulic properties. Plant, Cell Environ. 19, 911-927. https://doi.org/10.1111/j.1365-3040.1996.tb00456.x

Wrather, J.A., Koenning, S.R., 2006. Estimates of disease effects on soybean yields in the United States 2003 to 2005. J. Nematol. 38, 173-80. https://doi.org/10.1094/PHP-20090401-01-RS

Xia, Y., Mitchell, K., Ek, M., Cosgrove, B., Sheffield, J., Luo, L., Alonge, C., Wei, H., Meng, J., Livneh, B., Duan, Q., Lohmann, D., 2012a. Continental-scale water and energy flux analysis and validation for North American Land Data Assimilation System project phase 2 (NLDAS-2): 2. Validation of model-simulated streamflow. J. Geophys. Res. Atmos. 117, 1-23. https://doi.org/10.1029/2011JD016051

Xia, Y., Mitchell, K., Ek, M., Sheffield, J., Cosgrove, B., Wood, E., Luo, L., Alonge, C., Wei, H., Meng, J., Livneh, B., Lettenmaier, D., Koren, V., Duan, Q., Mo, K., Fan, Y., Mocko, D., 2012b. Continental-scale water and energy flux analysis and validation for the North American Land Data Assimilation System project phase 2 (NLDAS-2): 1. Intercomparison and application of model products. J. Geophys. Res. Atmos. 117, n/an/a. https://doi.org/10.1029/2011JD016048

Xu, X., Medvigy, D., Powers, J.S., Becknell, J.M., Guan, K., 2016. Diversity in plant hydraulic traits explains seasonal and inter-annual variations of vegetation dynamics in seasonally dry tropical forests. New Phytol. 212, 80-95. https://doi.org/10.1111/nph.14009

Yang, Yang, Anderson, M.C., Gao, F., Wardlow, B., Hain, C.R., Otkin, J.A., Alfieri, J., Yang, Yun, Sun, L., Dulaney, W., 2018. Field-scale mapping of evaporative stress 

indicators of crop yield: An application over Mead, NE, USA. Remote Sens. Environ. 210, 387-402. https://doi.org/10.1016/j.rse.2018.02.020

Zhao, M., A, G., Velicogna, I., Kimball, J.S., 2017. A Global Gridded Dataset of GRACE Drought Severity Index for 2002-14: Comparison with PDSI and SPEI and a Case Study of the Australia Millennium Drought. J. Hydrometeorol. 18, 2117-2129. https://doi.org/10.1175/JHM-D-16-0182

Zipper, S.C., Qiu, J., Kucharik, C.J., 2016. Drought effects on US maize and soybean production: Spatiotemporal patterns and historical changes. Environ. Res. Lett. 11. https://doi.org/10.1088/1748-9326/11/9/094021 